\title{
UNPLEASANT DEBT DYNAMICS: CAN FISCAL CONSOLIDATIONS RAISE DEBT RATIOS?
}

Working Papers 2015 



\title{
UNPLEASANT DEBT DYNAMICS: CAN FISCAL CONSOLIDATIONS RAISE DEBT RATIOS?
}

\author{
Working Papers 2015 \\ Gabriela Castro | Ricardo M. Félix | Paulo Júlio | José R. Maria
}

February 2015

The analyses, opinions and findings of these papers represent the views of the authors, they are not necessarily those of the Banco de Portugal or the Eurosystem

Please address correspondence to

Banco de Portugal, Economics and Research Department Av. Almirante Reis 71, 1150-012 Lisboa, Portugal T+351213130000 | estudos@bportugal.pt

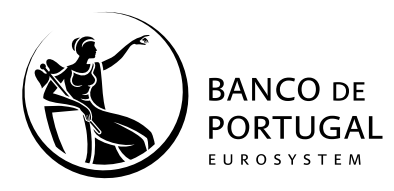

Lisbon, 2015 - www.bportugal.pt 
WORKING PAPERS | Lisbon 2015 • Banco de Portugal Av. Almirante Reis, 71 | 1150-012 Lisboa • www.bportugal.pt • Edition Economics and Research Department • ISBN 978-989-678-329-7 (online) • ISSN 2182-0422 (online) 


\title{
Unpleasant debt dynamics: \\ Can fiscal consolidations raise debt ratios?*
}

\author{
Gabriela Castro $^{\dagger} \quad$ Ricardo M. Félix ${ }^{\dagger} \quad$ Paulo Júlio $^{\ddagger} \quad$ José R. Maria $^{\dagger}$
}

February 20, 2015

\begin{abstract}
Using PESSOA, a medium-scale DSGE model for a small euro-area economy, we evaluate how fiscal adjustments impact short- and medium-term debt dynamics and output for alternative policy options, and budgetary and economic conditions. Fiscal adjustments may increase the public debt-to-GDP ratio in the short run, even for consolidations carried out in normal times in economies characterized by moderate indebtedness levels. Financial turmoils and hikes in the nationwide risk premia, coupled with high indebtedness levels and stiff fiscal measures, boost the output costs of fiscal consolidations and severely affect their effectiveness in bringing the public debtto-GDP ratio down in the short term. In the medium run credible fiscal adjustments entail a decline in the public debt ratio, though at potentially very large output losses when carried out under unfavorable budgetary and economic conditions.
\end{abstract}

JEL Classification: E12, E30, E62, H60

Keywords: Fiscal policy, Fiscal consolidation, Debt ratio, crisis, DSGE model, Euro Area, Small open economy

\section{Introduction}

The short-run impact of fiscal policies on the public debt-to-GDP ratio (hereinafter termed debt ratio) was not considered a key issue in developed countries until the inception of the Great Recession. Though fiscal consolidation has long been in the political agenda of European fiscal authorities, the existence of an apparently mechanical negative relationship between the consolidation effort and the debt ratio dictated the mild relevance of the topic. The change in the economic environment brought about by the Great Recession

\footnotetext{
${ }^{*}$ We thank the comments of Pietro Cova, Lara Wemans, Hugo Vilares, Luís Fonseca, and of all participants in the 2014 Central Bank Macroeconomic Modeling Workshop (Rome, October 2014). Paulo Júlio is pleased to acknowledge financial support from Fundação para a Ciência e a Tecnologia and FEDER/COMPETE (grant PEst-C/EGE/UI4007/2013). The views expressed in this article are those of the authors and do not necessarily reflect the views of Banco de Portugal or the Eurosystem. Any errors and mistakes are ours.

${ }^{\dagger}$ Economics and Research Department, Banco de Portugal.

${ }^{\ddagger}$ Economics and Research Department, Banco de Portugal; and Center for Advanced Studies in Management and Economics, Portugal. Corresponding author. Address: Rua Francisco Ribeiro, 2, 1150-165 Lisboa. E-mail: pfjulio@bportugal.pt
} 
changed the panorama. In an attempt to offset the adverse effects of the 2008 Financial Crisis on aggregate demand and thus on output, fiscal stimulus programmes were adopted worldwide. The debt ratio in the European Union increased from 59 percent in 2007 to 80 percent in 2010, and a similar development was experienced in the Euro Area as a whole, though some peripheral countries presented larger increments. By that time it was already clear that public debt was approaching an unsustainable level in some economies according to market participants, as suggested by the hike in sovereign debt spreads and credit default swaps. Expansionary fiscal policies therefore gave way to harsh consolidation strategies, aimed at restoring sovereign credibility and bringing down public debt. The effectiveness of such policies was limited at best, with debt ratios maintaining an upward trend, particularly in countries characterized by high indebtedness levels and engaging in harsh and front-loaded consolidation strategies. The prime examples are Ireland, Greece, and Portugal - countries which registered sharp increases in the debt ratio between 2010 and 2012, despite the implementation of financial assistance programmes implying stiff consolidation measures. Such outcome triggered the debate, both in the economics profession and in the media, about the effectiveness of fiscal adjustments in turbulent periods. ${ }^{1}$

Whether fiscal adjustments are able to put an halt to an upward trend in the debt ratio or even to revert it depends solely on the interaction between the consolidation effort - specifically the decline in the primary deficit ratio - and the strength of the socalled snowball effect - the increase in the value of the outstanding debt ratio induced by the wedge between the nationwide real interest rate and real GDP growth. ${ }^{2}$ A higher nominal interest rate raises interest outlays; a decline in GDP inflation boosts the real value of outstanding debt; and lower real GDP growth brings up the value of outstanding debt vis-à-vis the economy's real income. ${ }^{3}$

Using PESSOA, a medium-scale Dynamic Stochastic General Equilibrium (DSGE) model for a small euro-area economy encompassing non-Ricardian agents, nominal and real rigidities, and financial frictions, we study the dynamics of debt and output that follow credible fiscal consolidations for alternative policy options - namely different instrument mixes and consolidation paces - and budgetary conditions - viz initial indebtedness and fiscal effort levels. We address also the role played by changes in the economic environment, specifically temporary increases in the nationwide risk premia and financially induced crisis. It is worth emphasizing that our exercise does not aim at discussing whether fiscal adjustments should be pursued nor addresses the optimal debt target; we assume from

\footnotetext{
${ }^{1}$ See, for instance, the debate taking place at the Vox (http://www.voxeu.org).

${ }^{2}$ The long-run effects of fiscal consolidation is a topic with completely different implications, which we do not discuss here. For the long-run benefits of fiscal consolidation see Rother, Schuknecht, and Stark (2010), Mulas-Granados, Baldacci, and Gupta (2010), Barrios, Langedijk, and Pench (2010) and Almeida et al. (2013b).

${ }^{3}$ Fiscal consolidations leading to temporary increases in the debt ratio are often labeled in the literature as "self-defeating" fiscal consolidations (e.g. Boussard, Castro, and Salto 2013, Berti, De Castro, and Salto 2013, Eyraud and Weber 2013), though we avoid this wording throughout the article. It is our understanding that this expression appeals to the impossibility of bringing the debt ratio down at all, i.e. a defeat of consolidation measures due to unsustainable debt dynamics.
} 
the outset that fiscal authorities are forced to carry out a given fiscal consolidation plan. ${ }^{4}$ Moreover, we address only the case wherein fiscal adjustments are fully credible, i.e. fiscal authorities commit to lower the debt ratio to a new target level, and this is immediately taken into account by all economic agents.

We show that the snowball effect - triggered by the decline in real GDP growth and inflation - can outweigh the consolidation effort and bring about an increase in the debt ratio in the short term. This outcome may hold under regular conditions - for consolidations carried out in normal times in economies characterized by moderate indebtedness levelsbut it is substantially amplified by the initial outstanding debt ratio and the fiscal effort level. A higher initial outstanding debt ratio boosts the snowball effect. A larger effort level triggers a steeper decline in nominal GDP and thus a stronger snowball effect, whose short-run impact on the debt ratio may outweigh that of the stiffer adjustment. Fiscal consolidations performed in periods of crisis and preceded by hikes in the nationwide risk premia place a natural upward pressure in the snowball effect and thus in the debt ratio, forcing fiscal authorities to enlarge the fiscal package to comply with the new fiscal target. Stiffer consolidation measures, jointly with the unfavorable economic environment, entail larger output losses and pressure the debt ratio further upwards. In the medium run, credible fiscal adjustments successfully lower the debt ratio, though at potentially large output losses when carried out under unfavorable budgetary and economic conditions. Output losses can be mitigated if expenditure-side measures and back-loaded adjustments are used instead of revenue-side measures - which depress output for a protracted time period due to important distortionary effects - and front-loaded adjustments - which trigger more severe slumps. Expenditure-side measures and back-loaded adjustments generally entail, however, a larger short-run increase in the debt ratio. ${ }^{5}$

Our conclusions therefore hint that the hike in the nationwide risk premia and the decline in real GDP growth brought about by the Great Recession, coupled with high indebtedness levels registered throughout the turmoil and the stiff fiscal retrenchment that was carried out meanwhile, may have boosted the output losses of fiscal consolidations and severely affected their effectiveness in bringing the public debt ratio down vis-à-vis the pre-crisis period.

The article contributes towards the literature in at least two key dimensions. First, to our best knowledge, no other study explicitly addresses short-run debt dynamics in a medium-scale DSGE model. There are a few studies on the subject, but they rely solely on the equation for the law of motion of the debt ratio, an approach often requiring some assumptions as regards to the output effects of fiscal consolidations (e.g. Boussard, Castro, and Salto 2013, Eyraud and Weber 2013). Moreover, the role of inflation is often ignored in these studies, though it affects the real value of (non-contingent) debt and thus the

\footnotetext{
${ }^{4}$ The consequences of avoiding or postponing a pressing fiscal adjustment is a completely different topic which lies outside the scope of this article.

${ }^{5}$ Back-loaded fiscal adjustments may entail credibility issues, triggering hikes in the nationwide risk premia that adversely affect both the debt ratio and output. Under such environment, front-loaded consolidations may be preferred to back-loaded ones if credibility is at stake. Back-loaded adjustments could be made credible through the adoption of multiannual budget plans that enjoy a broad political support.
} 
debt ratio. Second, the spectrum of our analysis - encompassing the main drivers of the law of motion of debt as well as their interactions - captures key changes in economic and budgetary features brought about by the Great Recession, which, to our best knowledge, have not yet been jointly addressed elsewhere. The literature focuses mostly on the role played by the size of fiscal multipliers on debt dynamics, leaving aside other relevant factors and their interactions.

This article is organized as follows. Section 2 briefly reviews selected literature. Section 3 shortly describes the model. Section 4 presents the law of motion of the debt ratio within the context of PESSOA, and describes the fiscal consolidation exercise. Section 5 and Section 6 present and discuss the results. Section 7 concludes.

\section{Literature overview}

The bottom line amongst the articles that address short-run debt dynamics lies on the size of fiscal multipliers, which are likely to be larger in periods of crisis. Fiscal gains in crisis times may be wiped out by the decline in output, leading to short-run increases in the debt ratio that can last for several years, as argued by Boussard, Castro, and Salto (2013) and Eyraud and Weber (2013). The former study simulates debt paths under different economic characterizations after pinning down the equations characterizing debt dynamics. The latter performs a similar exercise, but complements the analysis with an empirical approach. The impact on the debt ratio is exacerbated if financial markets focus on short-term performance or are characterized by a substantial degree of myopia. Berti, De Castro, and Salto (2013) analyze the effects of fiscal consolidation envisaged in the 2013 Stability and Convergence Programmes presented by European Union Member States, under different assumptions on the underlying fiscal multipliers. The authors conclude that large fiscal multipliers entail temporary increases in the debt ratio following fiscal consolidation measures.

Along similar lines, Padoan, Sila, and van den Noord (2012) argue that some economies may be trapped in a bad equilibria, characterized by the simultaneous occurrence of high growing fiscal deficits and debt, high risk premia on sovereign debt, slumping economic activity, and plummeting confidence, all of which endowed with adverse feedback effects. In the short run the negative impact on demand may adversely affect market confidence to the extent that it depresses growth, hence affecting debt sustainability.

The effects on output can be minimized if smooth and gradual consolidations are preferred to front-loaded or aggressive ones, because sheltering economic activity is key to success. As a result, implementing fiscal consolidations in more favorable times, during periods of positive GDP growth, significantly reduces the impact of fiscal tightening measures on output. This argument is illustrated by Batini, Callegari, and Melina (2012) and Cherif and Hasanov (2012), the former using a threshold VAR structure to capture asymmetric macroeconomic developments during expansions and downturns, and the latter using a modified VAR framework with debt feedback effects, which suggests that the 
likelihood of a short-run increase in the debt-to-GDP ratio is much higher under weak economic conditions.

On the theoretical front, the few articles that focus on short-run debt dynamics simply pin down the equation for the law of motion of the debt ratio, given exogenous parameterizations for fiscal multipliers, initial debt, and interest rate developments (Boussard, Castro, and Salto 2013, Berti, De Castro, and Salto 2013, Eyraud and Weber 2013). This approach poses an important limitation, since one cannot properly take into account the feedback effects from the economic environment to the debt ratio, nor the specific design of fiscal policy measures. In addition, the understanding of the effects at work is rather limited. Forni, Monteforte, and Sessa (2009) develop and estimate a medium-scale DSGE model for the Euro Area to analyze the response of macro variables to a wide range of fiscal shocks. However, they do not focus on the debt dynamics of fiscal consolidations.

To our best knowledge, the effects of fiscal adjustments on short- and medium-term debt dynamics and output for alternative policy options, and budgetary and economic conditions, have not yet been addressed in a medium-scale DSGE model, wherein all effects of fiscal shocks are endogenously determined.

\section{A model for a small euro-area economy}

PESSOA is a New-Keynesian DSGE model for a monetarily-integrated small open economy. It features a multi-sectoral production structure, non-Ricardian characteristics, imperfect market competition, and a number of nominal and real rigidities that allow for realistic short-run dynamics and create room for welfare improving stabilization policies. In addition, the model contemplates financial frictions à la Bernanke, Gertler, and Gilchrist (1999), whereby financial shocks are transmitted and propagated to the real economy.

The economy is composed of nine types of agents: households, labor unions, capital goods producers, entrepreneurs, banks, intermediate goods producers (manufacturers), final goods producers (distributors), the government, and foreign agents (the rest of the monetary union). Figure 1 depicts the interactions between agents in PESSOA. The rest of the section briefly reviews the main features of the model. Additional details can be found in Almeida, Castro, and Félix (2010), Almeida et al. (2013b). The model's complete analytical solution is presented in Almeida et al. (2013a).

A constant number of households evolves according to the overlapping generations scheme first proposed in Blanchard (1985). They are subject to stochastic finite lifetimes and face an identical and constant probability of death, independent of age. ${ }^{6}$ Households rent labor services to labor unions, receiving in return a productivity adjusted wage rate, over which they pay a labor income tax. Labor productivity is assumed to decay over lifetime at a constant rate. Two types of households coexist in the model: asset holders, who are able to smooth consumption over lifetime by trading assets; and hand-to-mouth

\footnotetext{
${ }^{6}$ The probability of death can be also interpreted as the degree of "myopia" (Blanchard 1985, Frenkel and Razin 1996, Harrison et al. 2005, Bayoumi and Sgherri 2006). In other words, the future is seen as a period of lesser economic relevance.
} 
Figure 1: Interactions between agents in PESSOA.

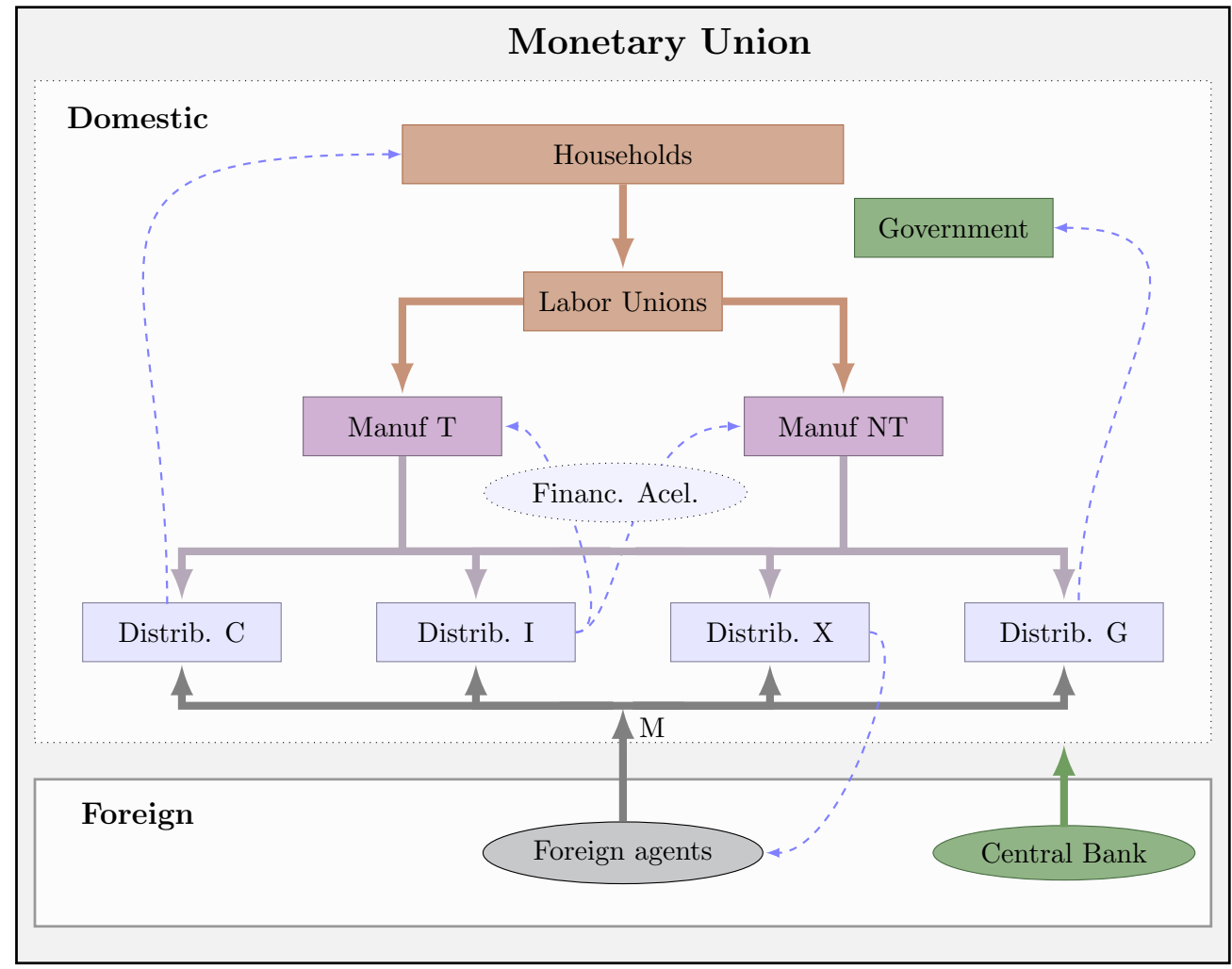

Notes: In the figure, $T$ stands for tradable goods, $N T$ for non-tradable goods, $C$ for consumption goods, $I$ for investment goods, $G$ for government consumption goods, $X$ for export goods, and $M$ for import goods. The financial accelerator mechanism comprises capital goods producers, entrepreneurs, and banks.

households (à la Galí, López-Salido, and Vallés 2007), who have no access to asset markets and therefore consume all their income in each and every period. All households are remunerated for labor services rented to labor unions and may receive transfers from both the government and abroad. In addition, asset holders earn interest on bond holdings and receive dividends from firms and a remuneration for financial services in the bankruptcy monitoring of firms. Households spend their income in the acquisition of consumption goods, over which they pay a consumption tax.

It is worth noting that PESSOA has intrinsic non-Ricardian features. Asset holders strongly prefer to finance government expenditure through debt issuance, since future taxes will be charged largely on yet-to-be born generations (Buiter 1988). Part of the debt held by current generations can therefore be used to finance private consumption during their lifetime, instead of being used to face future tax liabilities. Non-Ricardian effects are magnified by the life-cycle income profile, which shifts the proneness of agents towards paying taxes later, when labor income is lower, and by the lack of access to asset markets by hand-to-mouth households. Breaking the Ricardian equivalence is important to generate realistic private consumption responses to government expenditure shocks (Blanchard 1985, Galí, López-Salido, and Vallés 2007). In addition, the stochastic finite lifetime 
framework allows for the endogenous determination of the net foreign asset position of the economy in the steady state, by limiting the amount of assets/debt that households can accumulate (Harrison et al. 2005). This generates a positive correlation between public debt and the net foreign debt position, representing thus an appealing feature for the simulation of permanent fiscal shocks, as is the case of this article.

Labor unions hire labor services from households and sell them to manufacturers operating in the intermediate goods market. They are perfectly competitive in the input market and monopolistically competitive in the output market, and face adjustment costs on wage changes. Market power arises from the fact that labor unions supply differentiated, imperfectly substitutable labor services.

Manufacturers combine capital, rented from entrepreneurs, with labor services, hired from labor unions, to produce an intermediate good, which is thereafter sold to distributors. There are two types of manufacturers: those producing tradable goods, and those producing nontradable goods. Manufacturers are perfectly competitive in the input market and monopolistically competitive in the output market, and face quadratic adjustment costs on price changes. They pay social security taxes on their payroll and capital income taxes on profits.

Distributors combine domestic intermediate goods (both tradable and non-tradable) with imported goods to produce four types of differentiated final goods. Each type of final good is acquired by a unique type of costumer: consumption goods are acquired by households, investment goods by capital goods producers, government consumption goods by the government, and export goods by foreign distributors. Analogously to manufacturers, distributors are perfectly competitive in the input market and monopolistically competitive in the output market and face quadratic adjustment costs on price changes. They pay capital income taxes on profits.

Capital goods producers are the exclusive producers of capital. Before each production cycle, they buy the undepreciated capital from entrepreneurs and combine it with investment goods bought from distributors to produce new installed capital, which is thereafter sold to entrepreneurs. Capital goods producers face quadratic adjustment costs when changing investment levels and are assumed to operate in a perfectly competitive environment in both input and output markets.

The baseline model includes a financial transmission mechanism along the lines of Bernanke, Gertler, and Gilchrist (1999) and Christiano, Motto, and Rostagno (2010), whereby financial frictions affect the after-tax return on capital and therefore capital demand. The financial accelerator mechanism is composed of two agents, entrepreneurs and banks. At the end of each period, entrepreneurs buy the new capital stock from capital goods producers, and rent it, partially or entirely, to manufacturers, for usage in the production process. They do not have access to sufficient internal funds to finance desired capital purchases, but can cover the funding gap by borrowing from banks. Each entrepreneur faces an idiosyncratic shock that changes the value of the capital stock after the balance sheet composition has been decided, creating a risky environment. Entrepreneurs 
face two key decisions. First, they select the degree of leverage that maximizes the value of the firm, together with capital purchases. As net worth is taken as given, capital purchases directly determine the balance sheet composition and therefore leverage. Second, they must select the capital utilization rate that maximizes the present discounted value of after-tax profits related with the capital renting activity. Entrepreneurs pay a capital income tax on their profits.

Banks operate in a perfectly competitive environment. They are pure financial intermediaries, with the sole mission of borrowing funds from asset holders and lending to entrepreneurs. If an entrepreneur goes bankrupt, due to an adverse idiosyncratic shock, the bank must pay monitoring costs - which include all bankruptcy costs, such as auditing costs, asset liquidation or business interruption effects - to asset holders to be able to recover the value of the firm. Since capital acquisitions are risky, so are the loans of banks, who therefore charge a spread over the risk free rate to cover for bankruptcy losses. Even though individual loans are risky, the aggregate banks' portfolio is risk free since each bank holds a fully diversified portfolio of loans. The contract celebrated between the entrepreneur and the bank features a menu of state contingent interest rates, to be applied in all potential states of the world. Households loans are therefore risk free at all times, and thus they lend to banks at the risk free rate.

The government buys public consumption goods from distributors and performs lumpsum transfers to households. These activities are financed through tax levies on wage income, capital income, and households' consumption, and eventually through transfers from abroad. The government may also issue one-period bonds to finance expenditure, paying an interest rate on public debt. Wage income taxes-henceforth referred to as labor taxes - include the labor income tax paid by employees and the payroll tax paid by manufacturers. The government's budget constraint is

$$
B_{t}=i_{t-1} B_{t-1}+P_{t}^{\mathcal{G}} G_{t}+T R G_{t}-R V_{t}
$$

where $B_{t}$ denotes outstanding amount government bonds at time $t, i_{t}$ is the domestic interest rate, $P_{t}^{\mathcal{G}} G_{t}$ is the nominal value of government purchases, $T R G_{t}$ are lump-sum transfers, and finally, $R V_{t}$ represents total government revenues. These can be expressed as

$$
R V_{t}=\sum_{x} \tau_{t}^{x} \cdot\left(\operatorname{tax} \operatorname{base}_{t}^{x}\right)+T R E_{t}
$$

where $\tau_{t}^{x}$ is the tax rate levied on tax base ${ }_{t}^{x}$-households' consumption, employees' labor income, manufacturers' payroll, and firms' capital income - at time $t$ and $T R E_{t}$ are transfers from abroad. We assume that all government debt is held by domestic asset holders, i.e. there is full home bias (markets are incomplete). Households can, however, borrow from international debt markets to buy domestic government bonds. A fiscal rule, ensuring that debt follows a nonexplosive path, links the fiscal balance-to-GDP ratio, $S G_{t} / G D P_{t}$ to a pre-determined target level. Naturally, there is a one-to-one mapping between the target 
fiscal balance-to-GDP ratio and the target debt ratio, which can be obtained through the government's budget constraint. In this article we use transfers and labor taxes as endogenous fiscal instruments for expenditure and revenue-based consolidations, respectively. ${ }^{7}$

The rest of the world corresponds to the rest of the monetary union, and thus the nominal effective exchange rate is irrevocably set to unity. The rest of the monetary union is immune to domestic shocks, a consequence of the small-open economy framework, and hence domestic interest rates can only deviate from the monetary union's reference rate by an exogenous risk premium. The domestic economy interacts with the foreign economy via the goods market and the financial market. In the goods market, domestic distributors buy imported goods from abroad to be used in the production of final goods. Likewise for foreign distributors, who buy export goods from domestic distributors. In the international financial market, asset holders trade assets to smooth out consumption.

The model is closed by a set of conditions imposing market clearing for each and every period. PESSOA is calibrated to match Portuguese data. Besides historical data, calibration is based on information from studies on the Portuguese and euro area economies. Nonfinancial parameters and steady-state key ratios are based on Almeida et al. (2013a), with minor modifications. Castro et al. (2014) places a special focus on the calibrated of the entrepreneurial and financial sector. Further details can be found in the appendix.

\section{The fiscal consolidation strategy}

\subsection{The law of motion of the public debt ratio}

Fiscal consolidations may generate higher debt ratios in the short run if the reduction in government expenditures or the increase in government revenues lead to a substantial decline in economic activity or inflation. The debt-to-GDP ratio, $b_{t}$, evolves according to

$$
b_{t}=\frac{1+i_{t-1}}{\left(1+\pi_{t}\right)\left(1+g_{t}\right)} b_{t-1}-p s g_{t} \approx\left(1+i_{t-1}-\pi_{t}-g_{t}\right) b_{t-1}-p s g_{t}
$$

where $i_{t}$ is the nominal interest rate at time $t, \pi_{t}$ is the GDP inflation rate, $g_{t}$ is the real GDP growth rate, and $p s g_{t}$ denotes the primary balance-to-GDP ratio. A higher interest rate increases the government's interest outlays, thereby placing an upward pressure on the level of debt. On the opposite direction, higher GDP inflation decreases the real value of debt, whereas higher real GDP growth decreases the value of debt vis-à-vis the economy's output. The element $i_{t-1}-\pi_{t}-g_{t}$ is often termed the "snowball effect," to allure for the fact that past debt ratios place an upward cumulative pressure on the current debt ratio if the ex-post real interest rate, $i_{t-1}-\pi_{t}$, exceeds economy's growth rate, $g_{t}$. Subtracting

\footnotetext{
${ }^{7}$ The labor income tax rate is commonly selected as the endogenous fiscal policy instrument (Harrison et al. 2005, Kilponen and Ripatti 2006, Kumhof and Laxton 2007, Kumhof et al. 2010), though other possibilities - such as other tax rates, lump-sum transfers to households, government consumption or some combination of these - are naturally feasible.
} 
to (3) the steady-state version of the equation yields ${ }^{8}$

$$
\hat{b}_{t}-\hat{b}_{t-1}=\underbrace{\left(i_{t-1}-\pi_{t}-g_{t}\right) \hat{b}_{t-1}}_{\begin{array}{c}
\text { Snowball effect } \\
\text { over debt deviation }
\end{array}}+\underbrace{\left(\hat{i}_{t-1}-\hat{\pi}_{t}-\hat{g}_{t}\right) b^{\mathrm{ss}}}_{\begin{array}{c}
\text { Snowball effect } \\
\text { over steady-state debt }
\end{array}}-\underbrace{p \hat{s} g_{t}}_{\begin{array}{c}
\text { Consolidation } \\
\text { effort }
\end{array}}
$$

where $\hat{x}_{t}$ denotes deviations of $x_{t}$ from initial steady-state values at time $t$ and $b^{\text {ss }}$ is the initial steady-state debt-to-GDP ratio. The consolidation effort corresponds to the increase in primary balance actually implemented by fiscal authorities. The snowball element in Equation (4) can be decomposed into the effect triggered by the steady-state debt ratio and the effect triggered by the deviation in the debt ratio vis-à-vis the initial steady state. The size of the snowball effect is amplified with initial debt, and thus one should expect stronger debt dynamics in economies with larger outstanding debt amounts relative to nominal GDP. By feeding themselves into contemporaneous debt, past increases in the debt ratio relative to the steady-state level amplify the initial snowball effect.

In the short run the snowball effect may temporarily outweigh the consolidation effort implying $\hat{b}_{t}-\hat{b}_{t-1}>0$, mainly if fiscal instruments are extremely recessive or disinflationary and the initial debt ratio is large. The dynamics of the debt ratio are also influenced by other economic developments that affect the sovereign interest rate, real GDP growth, or GDP inflation, such as financial turmoils and hikes in the nationwide risk premia. In the medium term, as the business cycle effects unwind, changes in the debt ratio become mostly driven by the adjustment in the primary balance-to-GDP ratio, implying $\hat{b}_{t}-\hat{b}_{t-1}<0$.

Equation (4) can be alternatively restated as

$$
\hat{b}_{t}-\hat{b}_{t-1}=-\left(\pi_{t}+g_{t}\right) \hat{b}_{t-1}-\left(\hat{\pi}_{t}+\hat{g}_{t}\right) b^{\mathrm{ss}}-\hat{s} g_{t}
$$

where $\hat{s} g_{t}$ denotes the overall fiscal balance deviation from the initial steady-state level at time $t$. In this article we define the fiscal target in terms of overall fiscal balance, and thus changes in the sovereign interest rate are completely offset by changes in the primary fiscal balance-to-GDP ratio, such that the fiscal adjustment, $\hat{s} g_{t}$, equals the target adjustment at all times.

\subsection{The benchmark fiscal consolidation strategy and fiscal packages}

Our benchmark fiscal consolidation strategy consists in a permanent change in government expenditures or revenues, with the objective of achieving a 30 percentage points reduction in the debt-to-GDP ratio, from 90 to 60 percent. $^{9}$ The permanent fiscal shock corresponds to a 1.2 percentage points increase in the fiscal balance-to-GDP ratio, gradually implemented over time -50 percent is achieved roughly after 2 quarters and 90 percent after 2 years. This adjustment is depicted in the left panels of Figure 2. We assume perfect foresight and full credibility of fiscal authorities. The nationwide risk premium is

\footnotetext{
${ }^{8}$ From (3) one can obtain also the steady-state debt-to-GDP ratio, $b^{\mathrm{ss}}=p s g^{\mathrm{ss}} /\left(i^{\mathrm{ss}}-\pi^{\mathrm{ss}}-g^{\mathrm{ss}}\right)$.

${ }^{9}$ The former value is within the range registered in several advanced economies after the 2008's financial turmoil, whereas the latter reflects the target level embodied in the Maastricht convergence criteria.
} 
Figure 2: Benchmark fiscal consolidation and fiscal packages

(deviations from initial steady state)

_ Expenditure-based benchmark package

--- Government consumption-based package

....... Transfers-based package
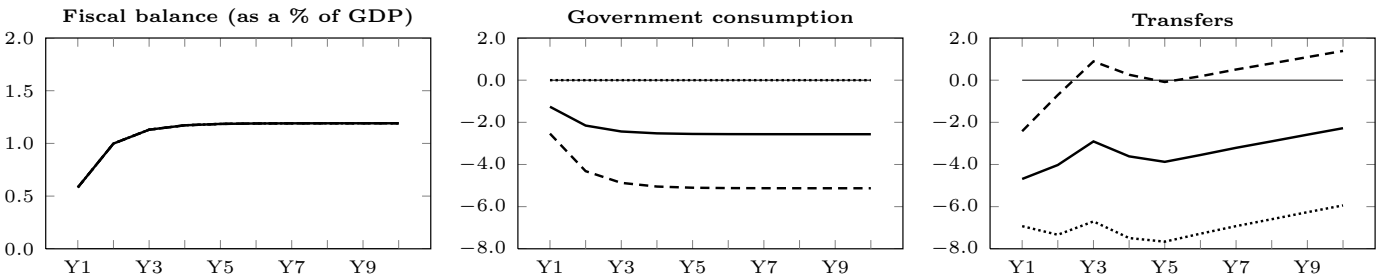

(a) Expenditure-based packages

- Revenue-based benchmark package

- - Consumption tax-based package

....... Labor tax-based package
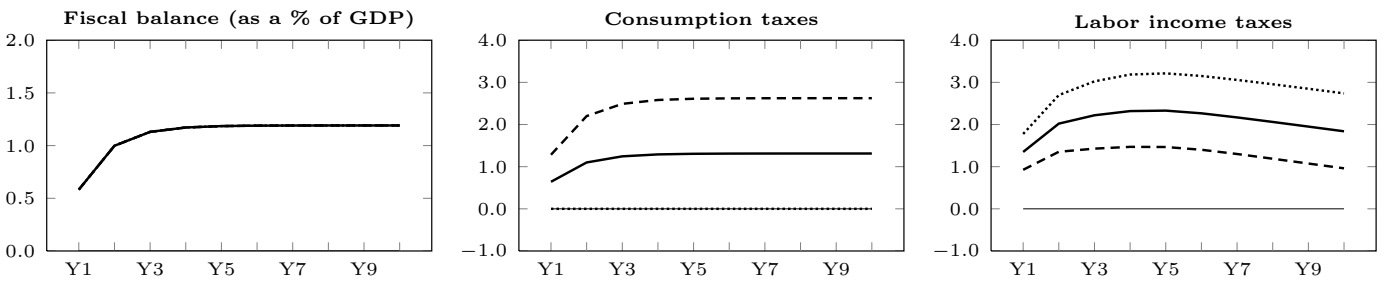

(b) Revenue-based packages

Notes: Values are expressed as percentage deviations from initial steady-state levels, except the fiscal balance, whose deviations are in percentage points. The government consumption-based (consumption tax-based) package consists in an exogenous permanent cut (increase) in government consumption (consumption taxes), amounting to 100 percent of the consolidation effort in terms of the initial ex-ante steady-state GDP, coupled with the endogenous adjustment of transfers (labor income taxes) required to achieve the new fiscal target. The transfers-based and the labor income tax-based packages consist respectively in the endogenous adjustment of transfers and of labor income taxes required to achieve the new fiscal target. The expenditure (revenue) benchmark fiscal package consists in an exogenous permanent cut (increase) in government consumption (consumption taxes), representing 50 percent of the adjustment effort in terms of the initial ex-ante steady-state GDP, coupled with the endogenous adjustment of transfers (labor income taxes).

exogenous and remains unaffected by the consolidation effort in the benchmark scenario. Thus, changes in the sovereign real interest rate are solely driven by domestic inflation developments.

We start by designing four distinct consolidation packages, plotted in Figure 2, each leaning towards a specific policy instrument: government consumption and transfers to households on the expenditure side; consumption taxes and labor income taxes on the revenue side. Following common options in the literature, we select transfers as the endogenous fiscal instrument for all expenditure-based adjustments (e.g. Harrison et al. 2005, Christiano, Eichenbaum, and Rebelo 2011), and labor income taxes for all revenuebased ones (e.g. Kilponen and Ripatti 2006, Kumhof and Laxton 2007, Kumhof et al. 2010). ${ }^{10}$ The government consumption-based (consumption tax-based) package consists in an exogenous permanent cut (increase) in government consumption (consumption taxes),

\footnotetext{
${ }^{10}$ Setting transfers or lump-sum taxes as endogenous policy tool is however equivalent.
} 
Figure 3: Selected macroeconomic impacts and debt dynamics: the instrument mix (deviations from initial steady state)

- Expenditure-based benchmark package

--- Government consumption-based package

....... Transfers-based package
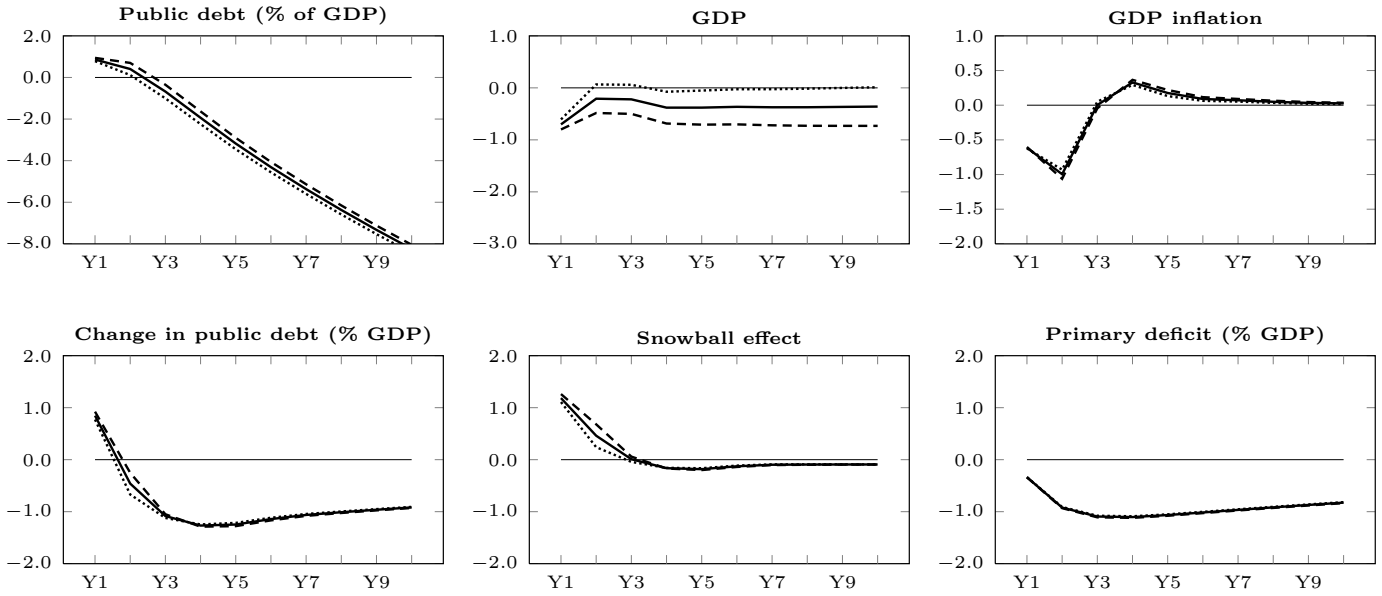

(a) Expenditure-based package

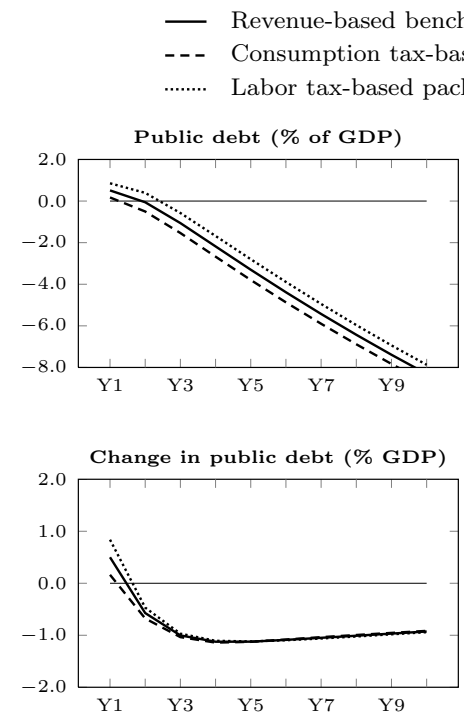

rk package

- - Consumption tax-based package

....... Labor tax-based package
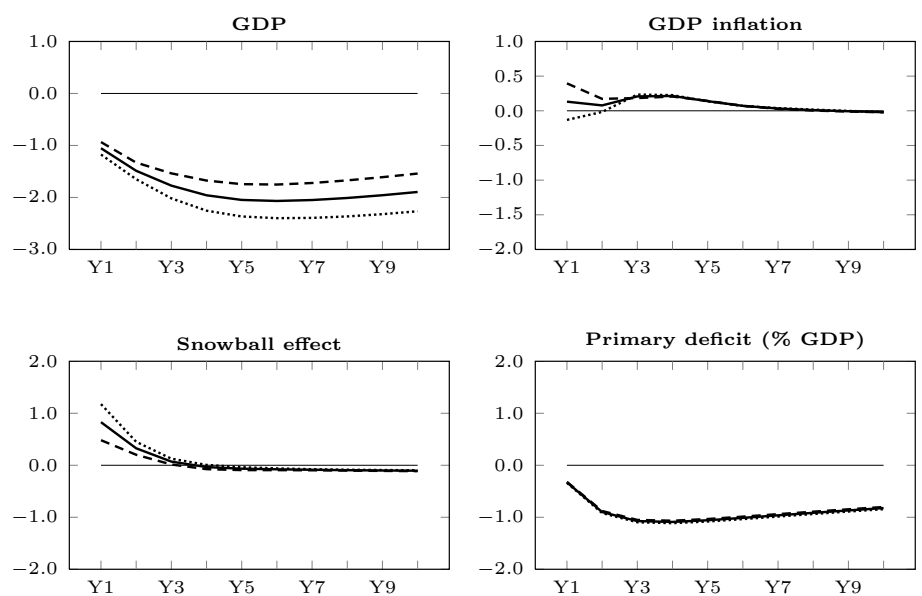

(b) Revenue-based package

Notes: See Figure 2.

amounting to 1.2 percentage points of the initial ex-ante steady-state GDP, gradually implemented over time exactly at the pace implied by the fiscal adjustment. Transfers (labor income taxes) adjust as necessary to achieve the new fiscal target. The transfers-based and the labor income tax-based packages consist respectively in the endogenous adjustment of transfers and of labor income taxes required to achieve the new fiscal target.

Figure 3 depicts the selected macroeconomic effects of these four policy options. ${ }^{11}$

\footnotetext{
${ }^{11}$ The snowball effect depicted in the figure comprises both the first and second elements of the right-hand side of Equation (4).
} 
The government consumption-based consolidation is slightly more recessive vis-à-vis the transfers-based one, though both show identical inflation dynamics. Debt dynamics are thus very similar. The former package has a direct effect on aggregate demand, whereas the latter affects aggregate demand indirectly via disposable income and wealth. This explains the more sizable GDP downfall for the government consumption-based consolidation. Both packages have similar second-order effects on aggregate demand. The decline in labor demand and therefore wages translates into a significant downfall in households' current income and wealth, and consequently in private consumption. Lower capital demand reduces the average return on capital, thereby increasing leverage and the costs of external financing, and placing more firms under financial distress. As a result, investment is hindered while firms rebalance their balance sheets. The transfers-based package reveals an additional channel on aggregate supply though, as households supply more labor to cope with the larger decline in income and wealth in this case. This extra effect explains why both consolidation packages display identical inflation dynamics albeit slightly distinct GDP dynamics. The inflation slowdown leads to price competitiveness gains and therefore to an improvement in the external account, allowing for a slight recovery in economic activity after the first year. ${ }^{12}$

The consumption tax-based adjustment yields a negligible increase in the debt ratio on impact, as the consolidation effort, together with higher inflation-which diminishes the real value of debt and thus restrains the snowball effect-largely offset the effects of lower growth. Higher inflation attenuates the increase in the external finance premium, thus preventing a sizable fall in the value of net worth and hampering the decline in capital demand and investment. However, the decline in employment and real wages pressure households' disposable income and wealth downwards, leading to a stiff reduction in private consumption. The growth rate of exported goods' prices - which is not subject to consumption taxes - declines, and the economy experiences some price competitiveness gains that slightly attenuate the negative output effects of fiscal policy. Contrarily, a labor tax-based adjustment triggers an increase in the debt ratio in the short run, mostly driven by the sharp decline in real GDP, since inflation remains roughly unchanged due to offsetting demand and supply-side effects. The demand side effects stem from the reduction in disposable income and wealth - explained by the sharp fall in wage income - and lower capital accumulation. The supply side effects stem from the simultaneous decline in labor supply and labor demand. The former is explained by the distortive nature of labor taxes, which trigger a substitution effect on the household side from consumption towards leisure. The latter is a natural consequence of lower demand. The economy experiences no important price competitiveness gains in this case.

These simulations show that fiscal adjustments may entail a short-run increase in the public debt ratio even when carried out in normal times. Expenditure-side instrumentsand in particular transfers - are less recessive than revenue-side instruments, though they

\footnotetext{
${ }^{12}$ In PESSOA, a cut in transfers shifts labor supply. In practice, however, transfers are to some extent targeted to pensioners, who do not actively supply labor. This feature is not captured by the model and may impose limitations on the interpretation of labor supply impacts.
} 
yield larger short-run increases in the debt ratio. This trade-off is explained by distinct inflation dynamics. Expenditure-based fiscal instruments, by depressing mostly aggregate demand, generate on impact large disinflationary pressures. These are absent from revenue-based consolidations and trigger more sizable snowball effects. Revenue-based adjustments impact GDP more strikingly and for a protracted time period, a fact explained by the time path of the highly distortive labor income taxes - the endogenous fiscal instrument in both packages - which increases for several years in order to bring the fiscal balance-to-GDP ratio up to the new target level before reverting to a downward trajectory.

To keep the analysis tractable while capturing the key features of fiscal adjustments, the remaining of the article focuses solely on two benchmark fiscal consolidation packages, also illustrated in Figure 2 and in Figure 3. The expenditure-based consolidation package consists in a permanent cut in government consumption, representing 50 percent of the fiscal effort in terms of the initial steady-state GDP, coupled with the endogenous adjustment of transfers required to achieve the new fiscal target. The revenue-based consolidation package comprises a permanent increase in consumption taxes, amounting to 50 percent of the fiscal effort in terms of the initial steady-state GDP, coupled with the endogenous adjustment of labor income taxes required to achieve the new fiscal target. Shocks in exogenous instruments are gradually implemented over time at the same pace as the adjustment in the fiscal balance-to-GDP ratio, i.e. 50 percent of the adjustment is achieved roughly after 2 quarters and 90 percent after 2 years.

\section{Debt dynamics and fiscal consolidation}

This section starts by studying how different consolidation paces and distinct budgetary conditions - namely initial indebtedness and fiscal effort levels - affect the short-run debt dynamics and the output costs of fiscal consolidations. The role played by changes in the economic environment, specifically temporary increases in the nationwide risk premia and financially induced crisis, is addressed thereafter. Results are strongly linked to the size of the snowball effect.

\subsection{The consolidation pace}

Figure 4 compares back-loaded fiscal adjustments with front-loaded ones. In the benchmark package, 50 percent of the increase in the fiscal balance-to-GDP ratio is achieved after 2 quarters and 90 percent after 2 years. The back-loaded package assumes that 50 percent of the increase in the fiscal balance-to-GDP ratio is achieved after 2 years and 90 percent after 8 years, whereas the front-loaded one considers that half of the adjustment in the fiscal balance-to-GDP ratio is carried out almost immediately and 90 percent by the mid of the first year. All the remaining features, including the change in the fiscal target, remain identical to the benchmark scenario.

Both the front-loaded and the back-loaded expenditure-side adjustments yield similar increases in the debt ratio on impact, as the former triggers a faster adjustment in the 
Figure 4: Selected macroeconomic impacts and debt dynamics: the consolidation pace (deviations from initial steady state)

mark package

- - - Back-loaded package

....... Front-loaded package
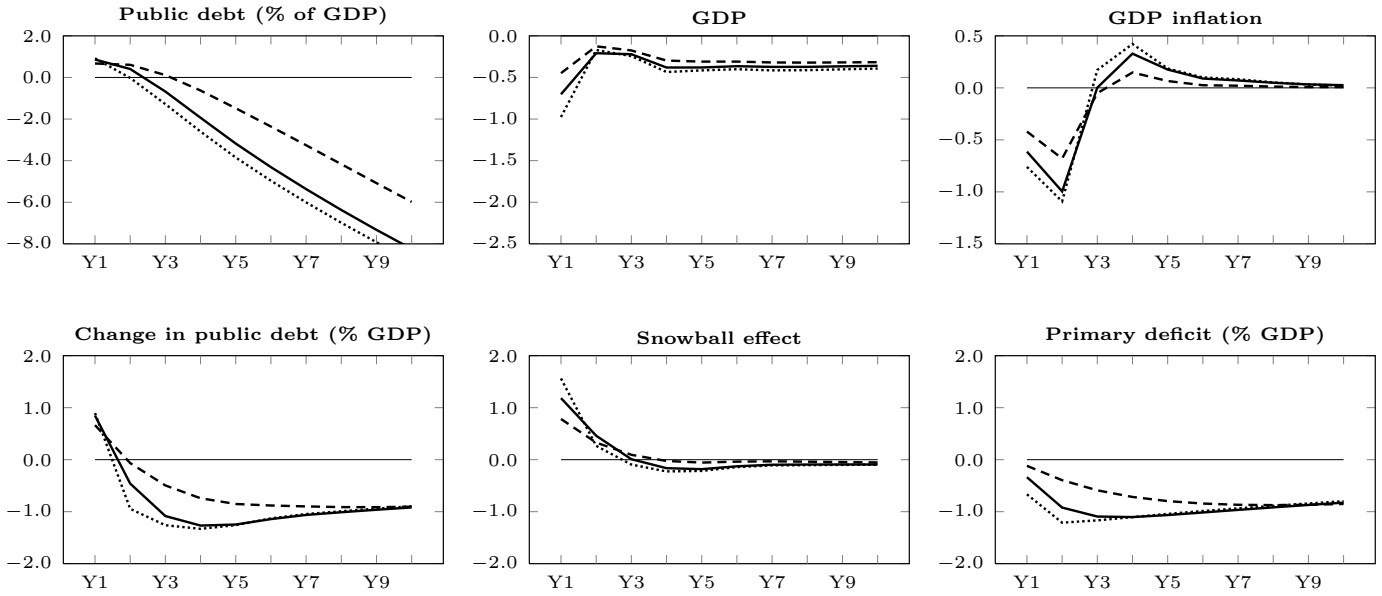

(a) Expenditure-based package
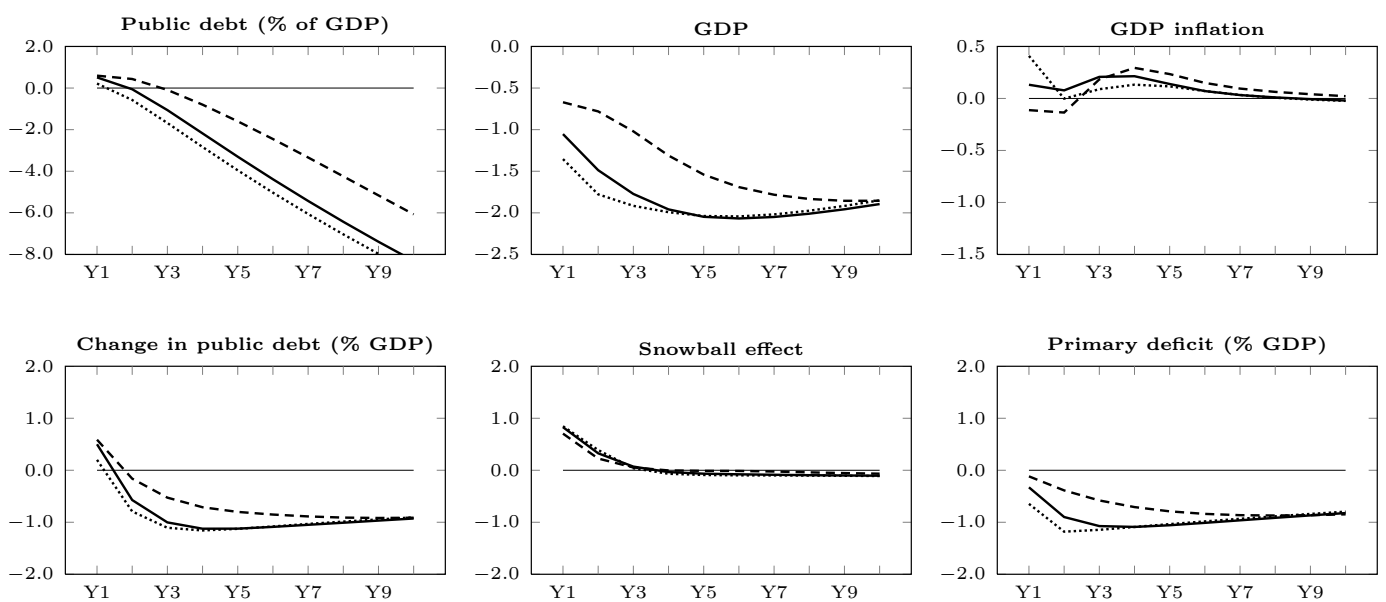

(b) Revenue-based package

Notes: The benchmark scenario considers that 50 percent of the increase in the fiscal balance-to-GDP ratio is achieved roughly after 2 quarters and 90 percent after 2 years. The back-loaded package assumes that 50 percent of the increase in the fiscal balance-to-GDP ratio is carried out after 2 years and 90 percent after 8 years, whereas the front-loaded package considers that half of the increase in the fiscal balance-to-GDP ratio is undertaken almost immediately and 90 percent by the mid of the first year.

primary fiscal balance but concomitantly originates a deeper recession and a larger inflation slowdown when compared with the latter. These business cycle effects place an additional upward pressure on the debt ratio - through the snowball effect - that offsets the effects of the larger consolidation effort. Thereafter, with the unwinding of the recessive and disinflationary effects, the debt ratio declines at a faster rate when fiscal measures are promptly carried out. Front-loading fiscal measures in a revenue-based package yield a sharper increase in consumption taxes, placing an additional upward pressure on inflation that offsets the effects of a deeper recession vis-à-vis the case wherein fiscal measures are 
back-loaded. The snowball effect is therefore roughly independent of the consolidation pace. The prompter implementation of revenue-based fiscal measures -implying a larger effort in the short run-yields a smaller increase in the debt-ratio in the first year and a faster decline thereafter.

To wrap up, front-loaded adjustments hasten the convergence to the debt target, and the debt ratio falls down below the initial steady-state value sooner when compared with back-loaded adjustments. This is however achieved at the cost of a deeper and more protracted recession, particularly in the case of revenue-based adjustments.

\subsection{Initial indebtedness}

Higher indebtedness levels - by increasing the size of the snowball effect - trigger larger short-run increases in the debt ratio for the same consolidation effort. Figure 5 depicts the benchmark scenario, which considers an initial debt ratio of 90 percent, alongside with two additional scenarios. One represents a low indebted economy where the initial steady-state debt is 60 percent of GDP, whereas the other represents a highly indebted economy with an initial debt ratio of 120 percent. ${ }^{13}$

Though the effects on real GDP and inflation are identical in all scenarios, in the most indebted economy the change in the debt ratio on impact is substantially larger than in the least indebted one. From Equation (4) it is clear that higher initial debt ratios trigger larger snowball effects whenever the change in the sovereign real interest rate exceeds

the change in real GDP growth, i.e., $\hat{i}_{t-1}-\hat{\pi}_{t}-\hat{g}_{t}>0$. This naturally implies larger increases in the debt ratio in the very short run, when the effects of fiscal consolidation on GDP and inflation are more severe. The intuition is that the wedge between the real interest rate - which determines the growth rate of real interest outlays - and real GDP growth - which defines how debt evolves relative to the economy's output - now impacts a larger outstanding debt amount. In addition, past increases in the debt ratio feed into forthcoming debt ratios, thus adding to the initial snowball effect. The debt ratio is brought down below the initial value when the effects of fiscal consolidation on the real interest rate and on real GDP growth fade out and the snowball effect loses momentum. While in the least indebted economy this occurs immediately after the first year, in the most indebted one the initial outcome is only reversed around the second or third year, for revenue- and expenditure-based consolidations, respectively.

\subsection{The fiscal effort level}

Figure 6 compares the outcome of three distinct fiscal effort levels. The benchmark scenario assumes a 30 percentage points decline in the debt ratio, from 90 to 60 percent, corresponding to a permanent medium-run increase in the target fiscal balance ratio of around 1.2 percentage points. The reduction in the debt ratio in the low effort scenario is 15 percentage points, from 90 to 75 percent, and in the high effort scenario 60 percentage

\footnotetext{
${ }^{13}$ The former value is the target debt ratio embodied in the Maastricht treaty, whereas the latter is closer to the debt ratios registered in some euro area economies.
} 
Figure 5: Selected macroeconomic impacts and debt dynamics: initial indebtedness (deviations from initial steady state)

- Benchmark scenario

- - - Low indebtedness

....... High indebtedness
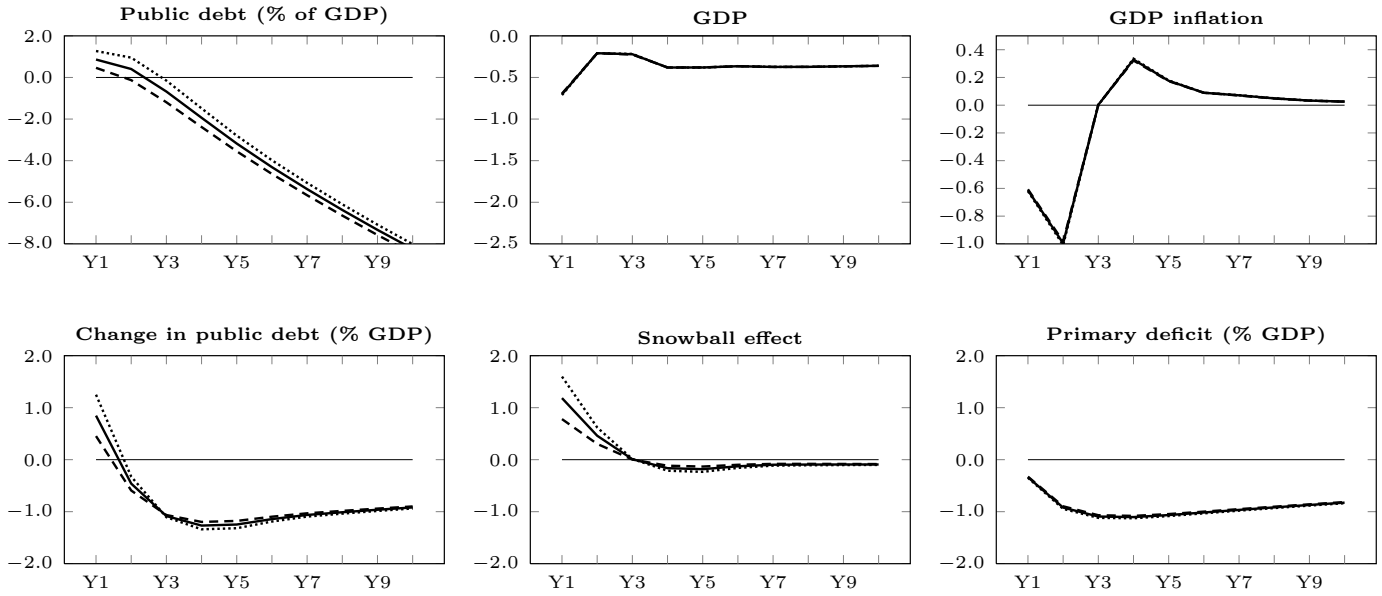

(a) Expenditure-based package
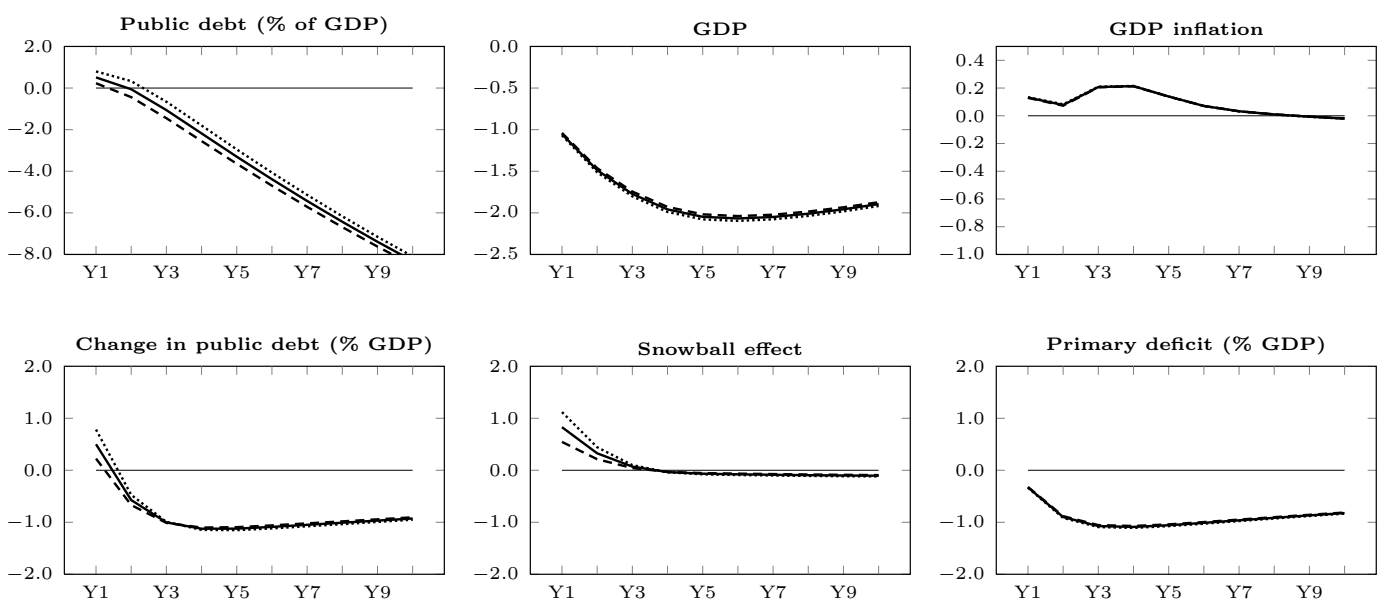

(b) Revenue-based package

Notes: The benchmark scenario considers an initial debt ratio of 90 percent. This value is 60 percent in the low indebtedness case, and 120 percent in the high indebtedness case.

points, from 90 to 30 percent. ${ }^{14}$ The former implies an increase in the medium-run target fiscal balance ratio of 0.6 percentage points, and the latter of 2.4 percentage points. All cases assume that exogenous fiscal instruments account for 50 percent of the fiscal effort in terms of the initial steady-state GDP and that half of the adjustment in the fiscal balance ratio is achieved after 2 quarters and 90 percent after 2 years.

Though common sense might suggest that stiffer consolidation strategies should lead to faster declines in the debt ratio, Figure 6 makes clear that, on impact, exactly the opposite

\footnotetext{
${ }^{14}$ What matters here is the effort level - defined as the percentage points reduction in the debt ratioand not the initial or final debt ratios. Results would be qualitatively identical if one assumes a different initial debt ratio.
} 
Figure 6: Selected macroeconomic impacts and debt dynamics: the effort level (deviations from initial steady state)
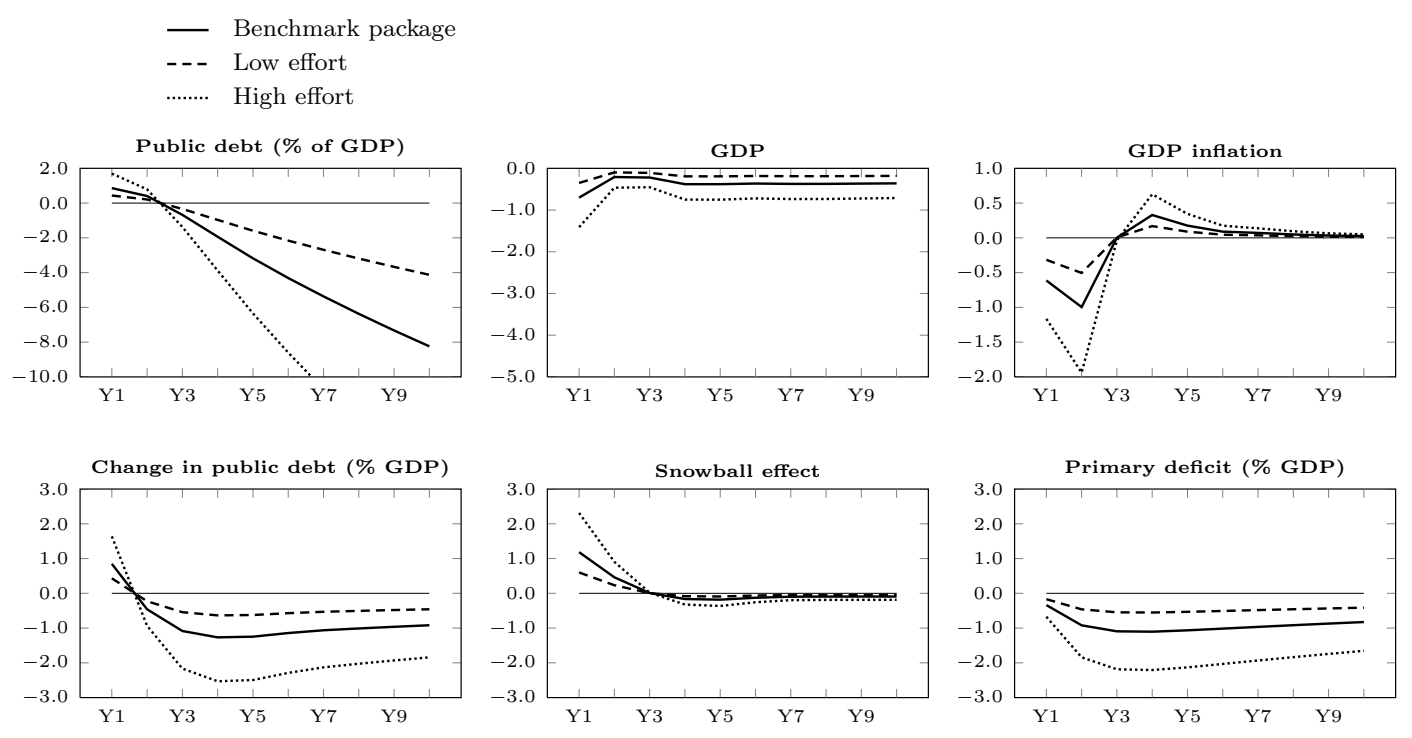

(a) Expenditure-based package
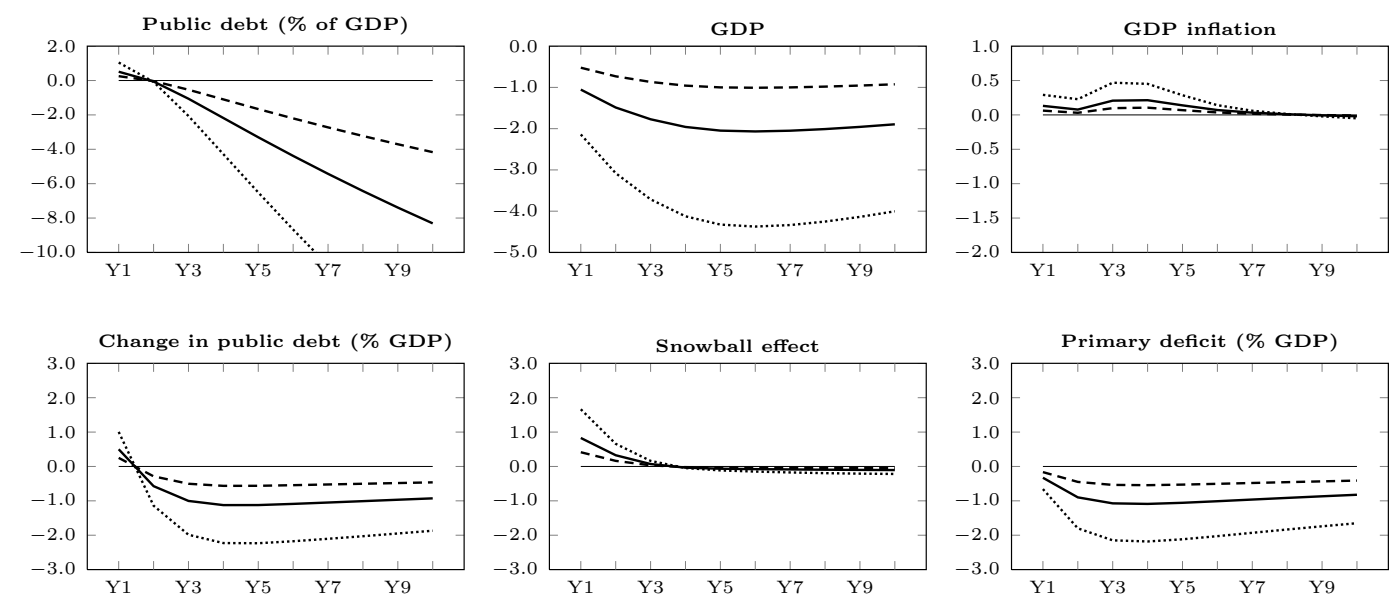

(b) Revenue-based package

Notes: The benchmark scenario considers a 30 percentage points reduction in the debt ratio, from 90 to 60 percent. The reduction in the debt ratio in the low effort scenario is 15 percentage points, from 90 to 75 percent, and in the high effort scenario 60 percentage points, from 90 to 30 percent.

outcome holds. In the short run, higher effort levels imply stronger adjustments in the debt level but concomitantly originate more severe recessions and, in the case of expendituredriven adjustments, larger inflation slowdowns. The more sizable snowball effect outweighs the stiffer increase in the fiscal balance, resulting in a more severe increase in the debt ratio. In other words, the denominator effect dominates and the debt ratio correlates positively with the effort level on impact. The effects are stronger for expenditure-based adjustments due to inflation dynamics. In the medium run, with the unwinding of the snowball effect, the debt ratio declines at a faster rate in the high effort case. The time 
length wherein the debt ratio remains above the initial steady-state level is independent of the fiscal effort, due to the faster decline in the debt ratio in the higher effort case after the first year.

Higher effort levels yield also larger output losses in the medium run. This is a natural consequence of the more severe fiscal adjustment. The effects are substantially stronger for revenue-based consolidations, due to the distortive nature of taxation. In particular, higher labor income taxes heighten the substitution effect on the household side from consumption towards leisure and strengthen the pace at which manufacturers substitute away from labor towards capital. The sharp decline in disposable income and wealth severely depress private consumption, and lower demand prospects outweigh the effects of the decrease in the relative price of capital, hampering investment. As a result, GDP experiences a protracted decline.

\subsection{The nationwide risk premia}

Fiscal consolidations are hindered if carried out in periods characterized by sizable nationwide risk premiums. Figure 7 plots the outcome of the expenditure- and revenue-side benchmark fiscal packages implemented in two distinct scenarios. In the first one the fiscal tightening is carried out under an unchanged nationwide risk premia, while in the second one it is preceded by a hike in the nationwide risk premia of 50 basis points. For simplicity, these events are assumed to take place contemporaneously, albeit sequentially, i.e. the hike in the nationwide risk premia is observed at the beginning of period $t$, and the government starts the fiscal retrenchment later in that same period. The fiscal package is assumed to be fully credible and triggers a gradual decline in the nationwide risk premia at a rate of 8 percent per quarter (corresponding to a half-life of 2 years). For reference, Figure 7 depicts also the impacts driven solely by an ad aeternum 50 basis points increase in the nationwide risk premia. In this scenario, we switch off the fiscal rule for 20 years, after which the government implements the required fiscal measures to bring the debt ratio down to the initial steady-state level. ${ }^{15}$

The hike in the nationwide risk premia pushes the interest rate on government bonds upwards, triggering a snowball effect. The policy-maker is forced to implement tighter consolidation measures - through the adjustment of endogenous fiscal instruments - to cope with larger interest outlays and concomitantly attain the new fiscal target. The hike in the nationwide risk premia per se-i.e. for the same GDP growth rate and inflation-has no direct impact on debt dynamics, since the fiscal target is set relative to the fiscal balance instead of the primary balance (recall the discussion on Equation 5).

The sharper short-run increase in the debt ratio registered when the adjustment is preceded by a hike in the nationwide risk premia stems therefore from the more severe decline in real GDP and, in the case of expenditure-based consolidations, also from the

\footnotetext{
${ }^{15}$ The time profile selected for the nationwide risk premia was calibrated using the percentage points difference in the implicit interest rate on government consolidated gross debt between Portugal and the Euro Area from 2011 onwards.
} 
Figure 7: Selected macroeconomic impacts and debt dynamics: the nationwide risk premia

(deviations from initial steady state)

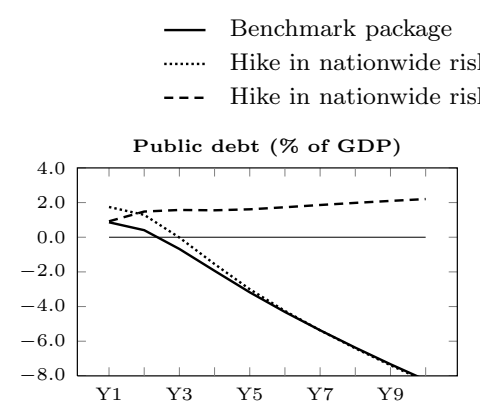

isk premia + benchmark package

...... Hike in nationwide in nationwide risk premia + no consolidation
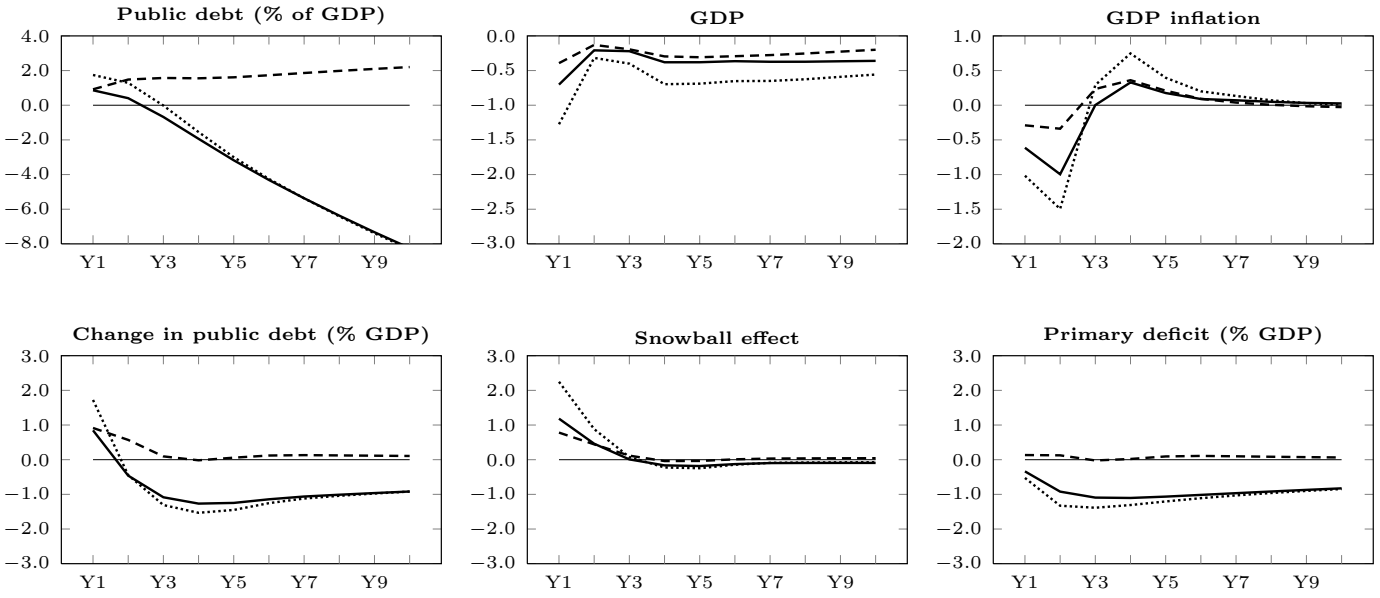

(a) Expenditure-based package
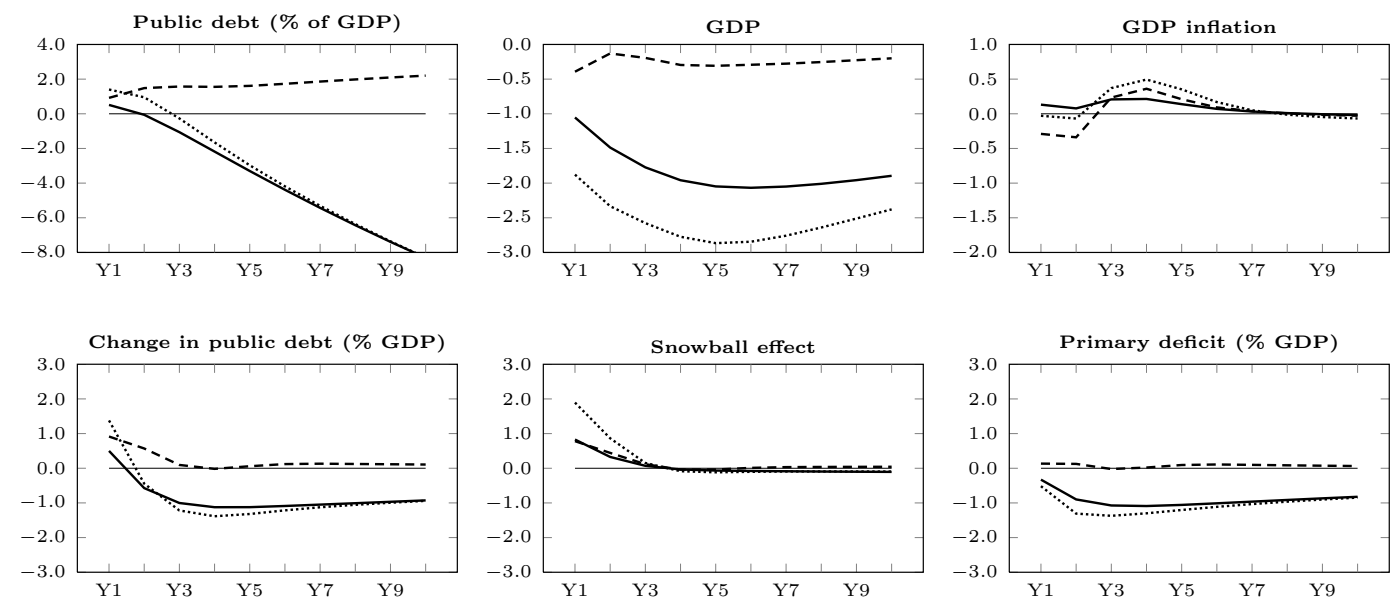

(b) Revenue-based package

Notes: The hike in the nationwide risk premia amounts to 50 basis points. This is assumed to hold ad aeternum in the case wherein no fiscal consolidation is carried out, and to gradually decay at a rate of 8 percent per quarter if followed by a fiscal retrenchment. Fiscal shocks are identical to the benchmark ones.

larger inflation slowdown. These business cycle effects push the snowball effect further upwards, increasing also the time length wherein the debt ratio remains above the initial steady-state level. The change in real GDP and inflation dynamics is driven both by the tighter adjustment, required to cope with larger interest outlays, and directly by the hike in the domestic interest rate.

Besides the negative effect on disposable income and wealth via lower transfers or higher taxes, harsher consolidation measures induct a stronger decline in labor demand. Wage income suffers an additional slump and compounds the effects of fiscal instruments 
on private consumption in the short run. In addition, the hike in the nationwide risk premia triggers a substitution effect, insofar as the return from savings - that is, the relative price of present consumption vis-à-vis future consumption-increases. Households' consumption is therefore depressed. Moreover, the persistent contraction in economic activity generates a reduction in the demand for capital and thus investment, depressing domestic demand.

Output recovers slightly as the nationwide risk premia returns to initial steady-state values - allowing a relief in fiscal tightening - and investment reverts from its downward trajectory. The recovery is prompter for the expenditure-based adjustment, as the recessive effects of the fiscal adjustment unwind faster and the economy enjoys price competitiveness gains under the less distortive expenditure-side instruments. For revenue-based adjustments, the recovery occurs only in the medium run, due to the time path of the highly distortive labor income taxes.

\subsection{Financial crisis}

Figure 8 plots the outcome of the expenditure- and revenue-side benchmark fiscal adjustments carried out in normal times and during a financial turmoil. In this latter case, the fiscal adjustment is preceded by a temporary shock to the degree of financial frictions, hereinafter termed financial shock. For simplicity, events are assumed to take place contemporaneously, albeit sequentially, i.e. the financial shock takes place at the beginning of period $t$, and the fiscal retrenchment starts later in that same period. The financial shock is calibrated such that the entrepreneurs' leverage ratio increases around 15 percent in the year of impact, and is assumed to gradually fade out at a rate of 8 percent per quarter (corresponding to a half-life of 2 years). ${ }^{16}$ For reference, we plot also the impacts driven solely by the financial shock. In this scenario, we switch off the fiscal rule for 20 years, after which fiscal authorities implement the required fiscal measures to bring the debt ratio down to the initial steady-state level.

Financial intermediaries are forced to raise credit spreads to cope with higher agency costs and larger bankruptcy losses entailed by the turbulence in the financial system. More expensive credit drives net worth downward, thus increasing leverage and forcing banks to further increase credit spreads to cover for the additional non-diversifiable risk. Entrepreneurs start a long-lasting deleveraging process, cutting back on capital acquisitions and slowly replacing external for internal finance while credit spreads remain at high levels. Investment is therefore hindered for a protracted time period. In addition, fiscal authorities must implement stiffer fiscal measures to offset the harmful effects of the financial turmoil on the fiscal balance-to-GDP ratio and attain the new fiscal target. The tighter adjustment - which adversely affects private consumption - together with the harmful effects brought about by the financial turmoil on investment, trigger a sharper

\footnotetext{
${ }^{16}$ Leverage increased around 23 percent for the Euro Area as a whole and around 60 percent on average across distressed euro-area economies (Portugal, Spain, Greece, Italy and Ireland) between 2000-07 and $2008-11$.
} 
Figure 8: Selected macroeconomic impacts and debt dynamics: financial crisis (deviations from initial steady state)

....... Financial crisis + benchmark package

-- - Financial crisis + no consolidation
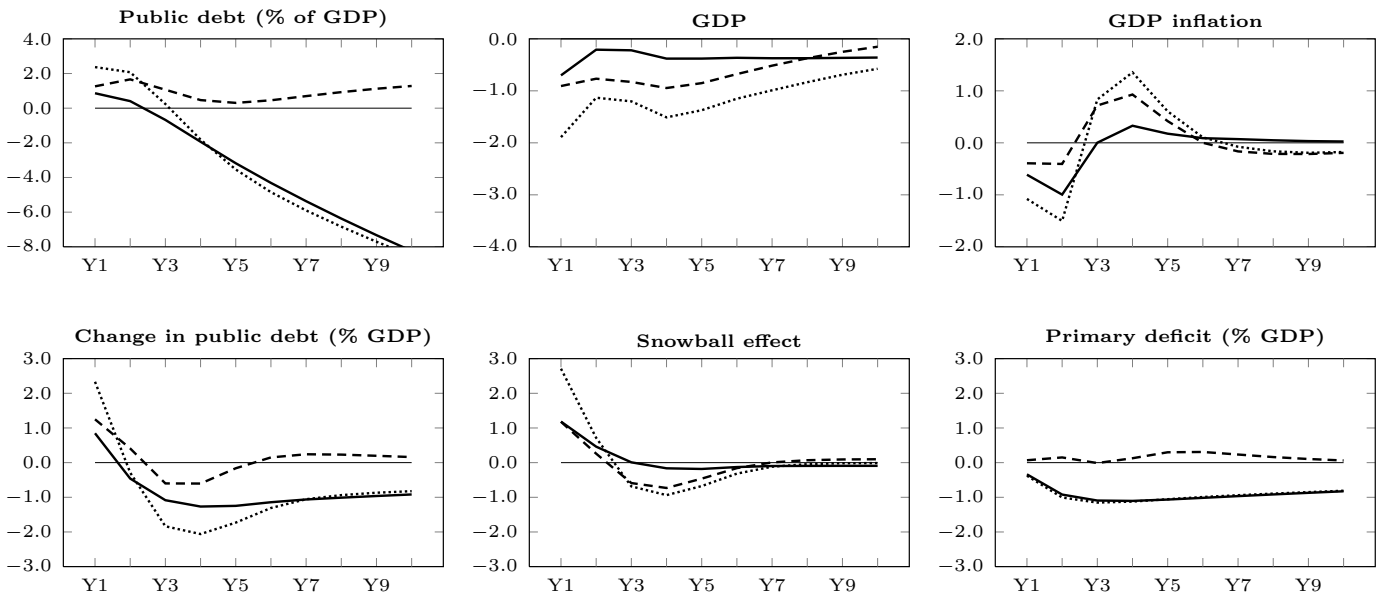

(a) Expenditure-based package
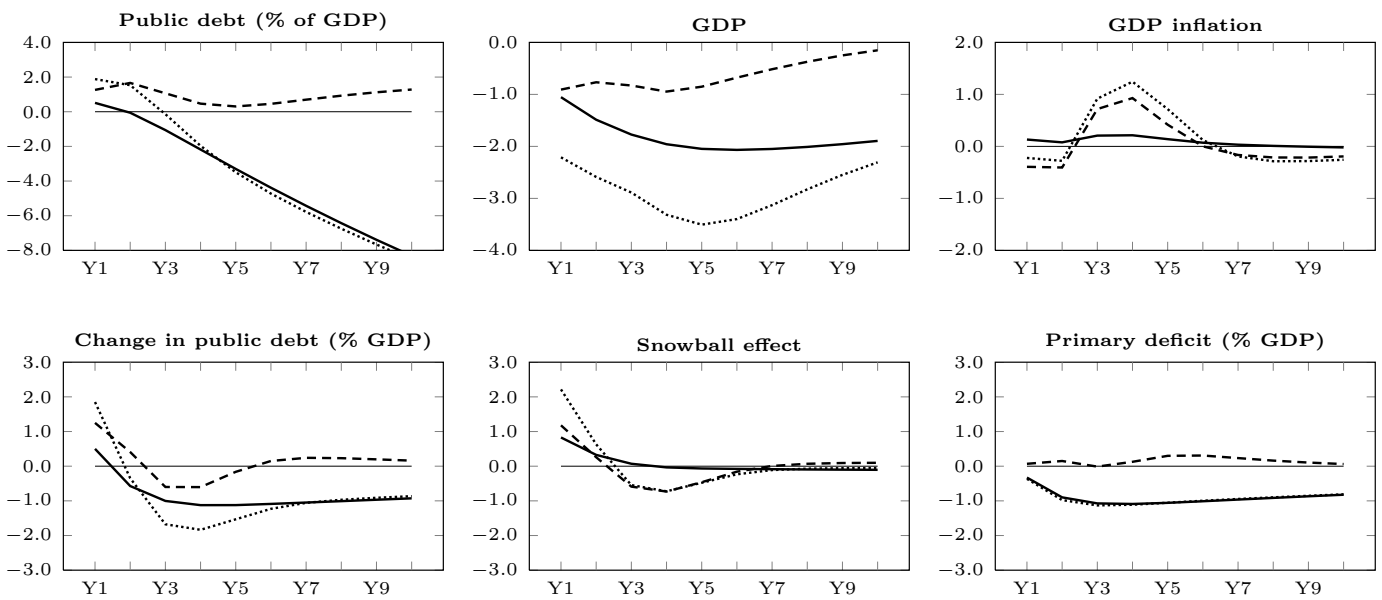

(b) Revenue-based package

Notes: The financial shock is calibrated to ensure an increase in the leverage ratio of entrepreneurial firms of around 15 percent in the year of impact. The shock gradually fades out at a rate of 8 percent per quarter. Fiscal shocks are identical to the benchmark ones.

decline in aggregate demand and thus output vis-à-vis a scenario in which the same fiscal package is implemented in normal times. The debt ratio is therefore more pressured upwards in the short run in the former scenario, through a larger snowball effect. Notice that a portion of the increase in the debt ratio is not driven by the fiscal adjustment per se, but instead by the financial turbulence. Output recovers slightly in the medium run, particularly for expenditure-based consolidations, reflecting the unwind of financial frictions and the concomitant slight relief in the fiscal tightening. 


\section{Discussion}

Our results suggest that the snowball effect - triggered by the decline in real GDP and also by disinflation in the case of expenditure-driven adjustments - can outweigh the consolidation effort and bring about an increase in the debt ratio in the short run. Though this result may hold under regular conditions - i.e. for consolidations carried out in normal times in economies characterized by moderate indebtedness levels - it is severely influenced by policy options, budgetary conditions, and the economic environment. This section delves further into the role played by the last two - taken as given by fiscal authorities - in short-run debt dynamics.

The inception of the Great Recession brought important changes to the budgetary conditions and to the economic environment faced by several countries, mainly in the euro area. In an attempt to offset the adverse effects of the 2008 Financial Crisis on aggregate demand and thus output, vast fiscal stimulus were employed worldwide. Debt ratios increased stiffly, and financial markets became progressively unrest with the financial capability of some sovereign states to honor the debt service, thus demanding larger credit spreads over sovereign debt. Expansionary fiscal policies quickly gave way to tight consolidation strategies that started to be carried out under extremely unfavorable budgetary and economic conditions. Debt ratios were at historically high levels and increasing; the financial crisis was still close to its pinnacle; and nationwide risk premiums reached their highest level since the inception of the Euro Area. Figure 9 illustrates how this unfavorable scenario might have affected the effectiveness of fiscal policies in bringing down the public debt ratio in the short and medium run, as well as the corresponding output losses.

Case I resembles fiscal adjustments in the pre-2008 crisis period. It considers a reduction in the debt ratio from 75 to 60 percent - a case corresponding to a comparatively low indebted economy that is able to implement a looser fiscal policy. Case II mimics fiscal adjustments carried out under unfavorable budgetary conditions, embodying a reduction in the debt ratio from 120 to 60 percent - a scenario corresponding to a fiscal adjustment in a highly indebted economy that adopts stiff policy measures. Case III adds an unfavorable economic environment to Case II, by considering that the fiscal adjustment is carried out during a financial turmoil and preceded by a hike in the nationwide risk premia. The risk premia shock and the financial shock are identical to the ones described in Sections 5.4 and 5.5, respectively. The instrument mix and the consolidation pace remain unchanged vis-à-vis the benchmark scenario in all cases, as these choices reflect policy options. The target debt ratio of 60 percent reflects the value embodied in the Maastricht treaty.

In the least indebted economy (Case I), both the expenditure- and revenue-based packages leave the debt ratio roughly unchanged on impact, reflecting the looser fiscal adjustment. Output losses are modest and inflation remains relatively stable, confining the size of the snowball effect. On the contrary, in the most indebted economy (Case II) the tighter fiscal adjustment entails a sharper increase in the debt ratio in the short run, in addition to a more sizable downfall in output, particularly for revenue-based consolida- 
Figure 9: Selected macroeconomic impacts and debt dynamics: the role played by unfavorable budgetary and economic conditions

(deviations from initial steady state)

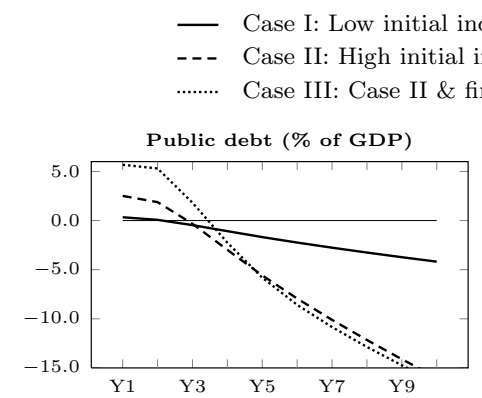

,

- Case II: High initial indebtedness \& high effort

..... Case III: Case II \& financial crisis \& hike in nationwide risk premia
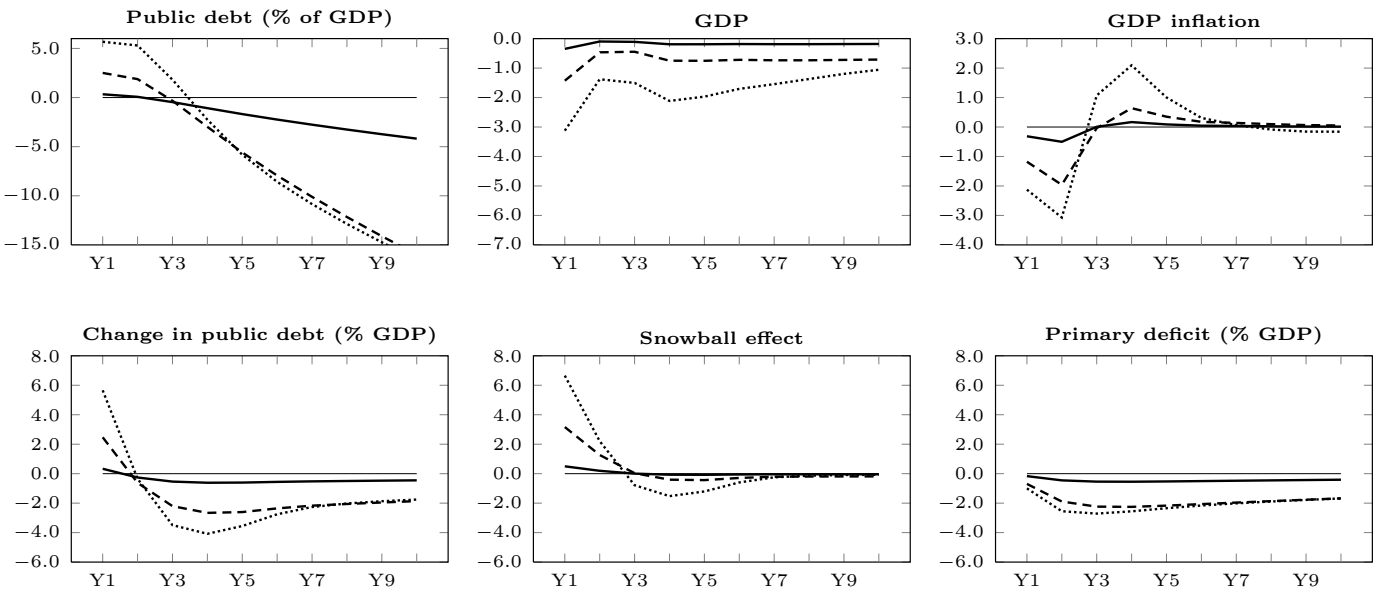

(a) Expenditure-based package
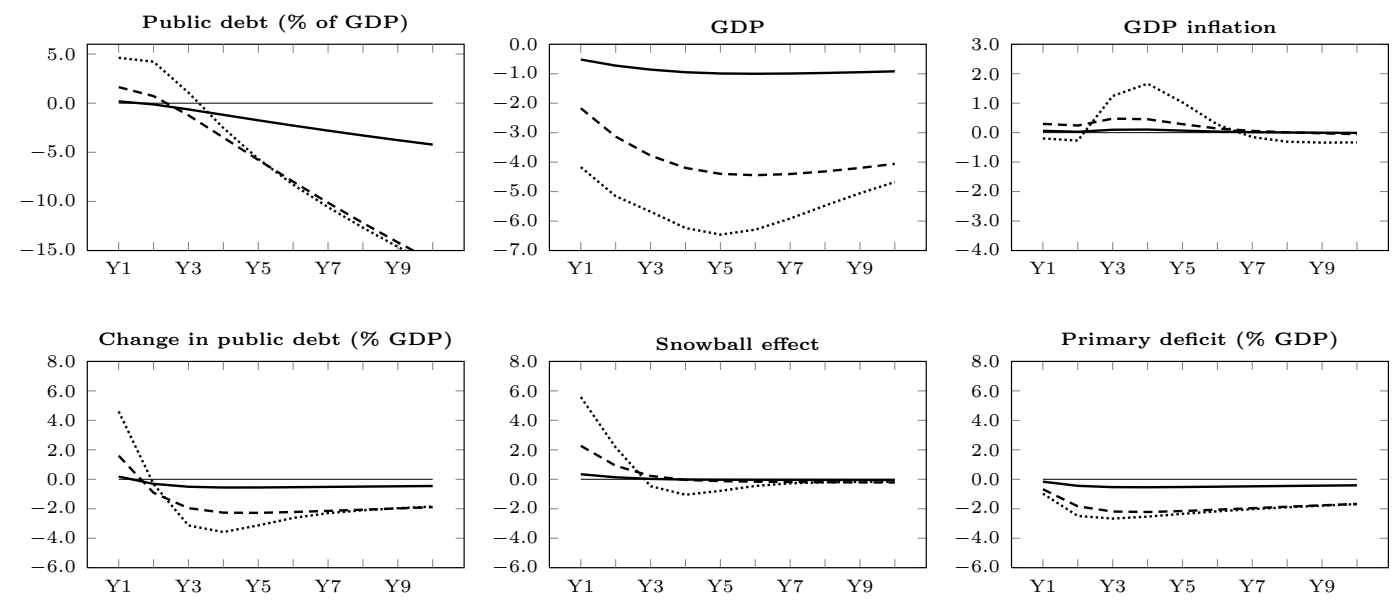

(b) Revenue-based package

Notes: Case I considers a reduction in the debt ratio from 75 to 60 percent, and Case II from 120 to 60 percent. Case III is similar to Case II, except that the adjustment is carried out during a financial turmoil and preceded by a hike in the nationwide risk premia.

tions. The snowball effect - reflecting the decline in nominal GDP and magnified by the initial indebtedness level - strongly outweighs the lower primary deficit ratio in the first year. The snowball effect dissipates swiftly with the unwinding of the recessive effects, and thus the consolidation effort largely determines the change in the debt ratio thereafter. When the fiscal adjustment is carried out during a financial turmoil and preceded by a hike in the nationwide risk premia (Case III), the debt ratio increases steeply in the first year and output losses become more severe. This outcome results from the recessive effects brought about by the adverse economic environment and by the sharper fiscal adjustment 
required to attain the new fiscal target under such conditions. Both heighten the size of the snowball effect and depress output considerably.

In the medium run the change in the debt ratio becomes primarily driven by the consolidation effort, as the snowball effect is short-lived. Hence, fiscal adjustments - even those requiring stiff policy measures - are always effective in bringing the public debt ratio down in this time span, though at potentially very large output losses. Fiscal consolidations carried out during a financial turmoil and preceded by hikes in the nationwide risk premia further contribute to depress output, though they are still effective in the medium run. Output losses can be mitigated if expenditure-side measures and back-loaded adjustments are preferred to revenue-side measures - which depress output for a protracted time period due to important distortionary effects - and front-loaded adjustments - which trigger more severe slumps. Expenditure-side measures and back-loaded adjustments generally entail, however, a larger short-run increase in the debt ratio.

\section{$7 \quad$ Concluding remarks}

Our simulations, performed with PESSOA - a DSGE model for a small euro-area economy shed light on some observed facts during the Great Recession, namely the apparent difficulty in bringing the public debt ratio down despite the stiff consolidation strategies that have been implemented in some countries.

The analysis suggests that fiscal adjustments may increase, rather than decrease, the public debt ratio in the short run. Though this outcome may hold under regular conditions - i.e. for consolidations carried out in normal times in economies characterized by moderate indebtedness levels - it is severely influenced by policy options, budgetary conditions, and the economic environment. These features determine the interaction between the consolidation effort - the change in the primary government deficit ratio - and the snowball effect - the change in the value of the outstanding debt ratio induced by changes in the difference between the sovereign real interest rate and real GDP growth. In addition, an unfavorable economic environment pushes the debt ratio upwards per se, hindering the fiscal adjustment and increasing the time span wherein the debt ratio remains above the initial steady-state level. Fiscal consolidations that trigger positive correlations between the debt ratio and the fiscal effort in the short run should thus not be regarded as unsuccessful or self-defeating, since this is a regular phenomenon. Only in the medium run, with the unwinding of the recessive and disinflationary effects, the snowball effect dissipates and the debt ratio becomes primarily driven by the consolidation effort.

Our exercise is not without some caveats. Results cannot be generalized to larger economies nor to the euro-area as a whole, since fiscal retrenchments in these cases will most likely trigger a monetary policy reaction from monetary authorities - implying interest and exchange rate adjustments. The dynamics of debt could be quite different, depending on the size of the interest rate change (which may be affected by the zero-lower bound). Trade channels would also play a role, since a fiscal retrenchment in a large euro- 
area economy would necessarily impact the external demand in the rest of the euro-area, with a negative impact on output. Moreover, the nationwide risk premia is treated as exogenous and thus independent of debt dynamics. Treating the nationwide risk premia as endogenous in a perfect foresight DSGE model is not a straightforward task, and usually requires some ad hoc, non-microfounded specification, that we chose not to perform. In particular, we leave outside the scope of the analysis the important case wherein the nationwide risk premia endogenously responds to the fiscal effort level or to public debt ratio. These are relevant directions for future research.

\section{References}

Almeida, Vanda, Gabriela Castro, Ricardo M. Félix, Paulo Júlio, and José R. Maria. 2013a. "Inside PESSOA - A detailed description of the model." Working Paper 16/2013, Banco de Portugal.

Almeida, Vanda, Gabriela Castro, Ricardo M. Félix, and José R. Maria. 2013b. "Fiscal consolidation in a small euro area economy." International Journal of Central Banking $9(4): 1-38$.

Almeida, Vanda, Gabriela Castro, and Ricardo Mourinho Félix. 2010. "Improving competition in the non-tradable goods and labour markets: the Portuguese case." Portuguese Economic Journal 9 (3):163-193.

Almeida, Vanda and Ricardo Félix. 2006. "Computing potential output and the outputgap for the Portuguese economy." Economic Bulletin Autumn:73-88.

Barrios, Salvador, Sven Langedijk, and Lucio Pench. 2010. "EU fiscal consolidation after the financial crisis. Lessons from past experiences." Economic Paper 418, Directorate General Economic and Monetary Affairs, European Commission.

Batini, Nicoletta, Giovanni Callegari, and Giovanni Melina. 2012. "Successful austerity in the United States, Europe and Japan." Working Paper 12/190, International Monetary Fund.

Bayoumi, T. and S. Sgherri. 2006. "Mr Ricardo's great adventure: Estimating fiscal multipliers in a truly intertemporal model." Working Paper 06/168, International Monetary Fund.

Bernanke, B.S., M. Gertler, and S. Gilchrist. 1999. "The financial accelerator in a quantitative business cycle framework." Handbook of macroeconomics 1:1341-1393.

Berti, Katia, Francisco De Castro, and Matteo Salto. 2013. "Effects of fiscal consolidation envisaged in the 2013 Stability and Convergence Programmes on public debt dynamics in EU Member States." Economic Paper 504, Directorate General Economic and Monetary Affairs, European Commission.

Blanchard, Olivier. 1985. "Debts, deficits and finite horizons." Journal of Political Economy 93 (2):223-247.

Boussard, Jocelyn, Francisco Castro, and Matteo Salto. 2013. "Fiscal multipliers and public debt dynamics in consolidations." In Public Debt, Global Governance and Economic Dynamism, edited by Luigi Paganetto. Springer Milan, 167-211. 
Buiter, Willem. 1988. "Death, birth, productivity growth and debt neutrality." The Economic Journal 98 (391):279-293.

Castro, Gabriela. 2006. "Consumption, disposable income and liquidity constraints." Economic Bulletin Summer:75-84.

Castro, Gabriela, Ricardo M. Félix, Paulo Júlio, and José R. Maria. 2014. "Financial Segmentation Shocks." Mimeo, Banco de Portugal.

Cherif, Reda and Fuad Hasanov. 2012. "Public debt dynamics: The effects of austerity, inflation, and growth shocks." Working Paper 12/230, International Monetary Fund.

Christiano, Lawrence, Martin Eichenbaum, and Sergio Rebelo. 2011. "When is the government spending multiplier large?" Journal of Political Economy 119 (1):78-121.

Christiano, Lawrence, Roberto Motto, and Massimo Rostagno. 2010. "Financial factors in economic fluctuations." Working Paper 1192, European Central Bank.

Coenen, Gunther, Peter McAdam, and Roland Straub. 2007. "Tax reform and labourmarket performance in the euro area: a simulation-based analysis using the New AreaWide Model." Working Paper 747, European Central Bank.

Erceg, Christopher J., Dale W. Henderson, and Andrew T. Levin. 2000. "Optimal monetary policy with staggered wage and price contracts." Journal of Monetary Economics 46 (2):281-313.

Eyraud, Luc and Anke Weber. 2013. "The challenge of debt reduction during fiscal consolidation." Working Paper 13/67, International Monetary Fund.

Fagan, Gabriel, Vítor Gaspar, and Alfredo Pereira. 2004. "Macroeconomic adjustment to structural change." In Monetary strategies for joining the euro, edited by György Szapary and Jürgen von Hagen. Edward Elgar, 168-217.

Forni, Lorenzo, Libero Monteforte, and Luca Sessa. 2009. "The general equilibrium effects of fiscal policy: Estimates for the euro area." Journal of Public Economics 93 (3):559585.

Frenkel, Jacob and Assaf Razin. 1996. Fiscal Policies and growth in the world economy. The MIT Press, 3rd ed.

Galí, Jordi, J David López-Salido, and Javier Vallés. 2007. "Understanding the effects of government spending on consumption." Journal of the European Economic Association $5(1): 227-270$.

Harrison, Richard, Kalin Nikolov, Meghan Quinn, Gareth Ramsay, Alasdaur Scott, and Ryland Thomas. 2005. The Bank of England Quarterly Model. Bank of England.

Høj, Jens, Miguel Jimenez, Maria Maher, Giuseppe Nicoletti, and Mikael Wise. 2007. "Product market competition in OECD countries: Taking stock and moving forward." Economics Department Working Paper 575, Organisation for Economic Co-operation and Development.

Kilponen, Juha and Antti Ripatti. 2006. "Labour and product market competition in a small open economy: Simulation results using a DGE model of the Finnish economy." Discussion Paper 5/2006, Bank of Finland. 
Kumhof, Michael and Douglas Laxton. 2007. "A party without a hangover? On the effects of U.S. government deficits." Working Paper 07/202, International Monetary Fund.

Kumhof, Michael, Dirk Muir, Susanna Mursula, and Douglas Laxton. 2010. "The Global Integrated Monetary and Fiscal Model (GIMF) - Theoretical structure." Working Paper 10/34, International Monetary Fund.

Mata, José, António Antunes, and Pedro Portugal. 2010. "Borrowing patterns, bankruptcy and voluntary liquidation." Working Paper 27, Banco de Portugal.

Mulas-Granados, Carlos, Emanuele Baldacci, and Sanjeev Gupta. 2010. "Restoring debt sustainability after crises: Implications for the fiscal mix." Working Paper 10/232, International Monetary Fund.

Musso, Alberto and Thomas Westermann. 2005. "Assessing potential output growth in the euro area: A growth accounting perspective." Occasional Paper 22, European Central Bank.

Padoan, Pier, Urban Sila, and Paul van den Noord. 2012. "Avoiding debt traps: Financial backstops and structural reforms." Working Papers 976, Organization for Economic Cooperation and Development.

Proietti, Tommaso and Alberto Musso. 2007. "Growth accounting for the euro area: A structural approach." Working Paper 804, European Central Bank.

Rother, Philipp, Ludger Schuknecht, and Jürgen Stark. 2010. "The benefits of fiscal consolidation in uncharted waters." Occasional Paper 121, European Central Bank. 


\section{Appendices}

\section{A Calibration}

PESSOA is calibrated to match data for the Portuguese and euro-area economies. Some parameters are exogenously set by taking into consideration common options in the literature, available historical data, or empirical evidence. Others are endogenously determined within the model, with the objective of matching desired features, for instance the consumption- or investment-to-GDP ratios.

The annual growth rate of the labor-augmenting productivity is set to 2 percent, which is a plausible estimate for potential output growth in both Portugal and the euro area (Almeida and Félix 2006, Musso and Westermann 2005, Proietti and Musso 2007). Steady-state inflation stands at 2 percent per year and the euro area nominal interest rate at 4.5 percent (Coenen, McAdam, and Straub 2007). Steady-state tax rates, transfers from the rest of the euro area, government consumption, and government transfers are calibrated to match actual data.

Households parameters are largely based on Fagan, Gaspar, and Pereira (2004), Harrison et al. (2005), Kumhof and Laxton (2007) and Kumhof et al. (2010). Consumption shares are calibrated to ensure a unitary elasticity of labor supply to real wage. The instant probability of death and the productivity decay rate are assumed to be identical, implying an average lifetime and an expected working life of 25 years. The share of hand-to-mouth households is broadly in line with the estimates for Portugal presented in Castro (2006).

The depreciation rate of capital is calibrated by taking into account actual data on the investment-to-GDP ratio. The unitary elasticity of substitution between capital and labor in the production function takes into account the actual labor income share. The steadystate price markup of tradable and non-tradable goods is calibrated using OECD product market regulation indicators, as well as the correlation between tradable and non-tradable goods markups and product market regulation indicators found in Høj et al. (2007). The elasticity of substitution between domestic tradable goods and imported goods is assumed to be identical across firms and set above unity (Coenen, McAdam, and Straub 2007, Harrison et al. 2005, Erceg, Henderson, and Levin 2000, Kumhof et al. 2010). The degree of monopolistic competition amongst distributors is lower than among manufacturers.

The leverage ratio of entrepreneurs, the probability of default, and the return on capital - assumed identical for the tradable and non-tradable sectors-are approximated with aggregate Portuguese historical features. The leverage ratio is 100 percent. The same value is used in Bernanke, Gertler, and Gilchrist (1999) and Kumhof et al. (2010). The probability of default - 8 percent - is relatively close to the exit rates reported in Mata, Antunes, and Portugal (2010), and in line with the value found in Kumhof et al. (2010). The loan rate spread of 175 basis points is close to the average value for the 2000-07 period.

Further details on the calibration can be found in Almeida et al. (2013a). Castro et al. (2014) places a special focus on the calibration of the financial sector. 


\section{WORKING PAPERS}

\section{3}

01|13 Macroeconomic forecasting using lowfrequency filters

João Valle | Azevedo, Ana Pereira

02|13 Everything you always wanted to know about sex discrimination

Ana Rute Cardoso | Paulo Guimarães | Pedro Portugal

03|13 Is there a role for domestic demand pressure on export performance?

Paulo Soares Esteves | António Rua

04|13 Ageing and fiscal sustainability in a small euro area economy

Gabriela Castro | José R. Maria | Ricardo Mourinho Félix | Cláudia Rodrigues Braz

05|13 Mind the gap! The relative wages of immigrants in the Portuguese labour market

Sónia Cabral | Cláudia Duarte

06|13 Foreign direct investment and institutional reform: Evidence and an application to Portugal

Paulo Júlio | Ricardo Pinheiro-Alves | José Tavares

07|13 Monetary policy shocks: We got news!

Sandra Gomes | Nikolay Iskrev | Caterina Mendicino

08|13 Competition in the Portuguese Economy: Estimated price-cost margins under imperfect labour markets

João Amador | Ana Cristina Soares

09|13 The sources of wage variation: a threeway high-dimensional fixed effects regression model

Sonia Torres | Pedro Portugal | John T. Addison | Paulo Guimarães
10|13 The output effects of (non-separable) government consumption at the zero lower bound

Valerio Ercolani | João Valle e Azevedo

11|13 Fiscal multipliers in a small euro area economy: How big can they get in crisis times?

Gabriela Castro | Ricardo M. Felix | Paulo Julio | Jose R. Maria

12|13 Survey evidence on price and wage rigidities in Portugal

Fernando Martins

13|13 Characterizing economic growth paths based on new structural change tests Nuno Sobreira | Luis C. Nunes | Paulo M. M. Rodrigues

14|13 Catastrophic job destruction Anabela Carneiro | Pedro Portugal | José Varejão

15|13 Output effects of a measure of tax shocks based on changes in legislation for Portugal

Manuel Coutinho Pereira | Lara Wemans

16|13 Inside PESSOA - A detailed description of the model

Vanda Almeida | Gabriela Castro | Ricardo M. Félix | Paulo Júlio | José R. Maria

17|13 Macroprudential regulation and macroeconomic activity

Sudipto Karmakar

18|13 Bank capital and lending: An analysis of commercial banks in the United States

Sudipto Karmakar | Junghwan Mok 


\section{4}

1|14 Autoregressive augmentation of MIDAS regressions

Cláudia Duarte

2|14 The risk-taking channel of monetary policy - exploring all avenues

Diana Bonfim | Carla Soares

3|14 Global value chains: Surveying drivers, measures and impacts

João Amador | Sónia Cabral

4|14 Has US household deleveraging ended? a model-based estimate of equilibrium debt

Bruno Albuquerque | Ursel Baumann | Georgi Krustev

5|14 The weather effect: estimating the effect of voter turnout on electoral outcomes in italy

Alessandro Sforza

6|14 Persistence in the banking industry: fractional integration and breaks in memory Uwe Hassler, Paulo M.M. Rodrigues, Antonio Rubia

7|14 Financial integration and the great leveraging

Daniel Carvalho

8|14 Euro area structural reforms in times of a global crisis

Sandra Gomes

9|14 Labour demand research: towards a better match between better theory and better data

John T. Addison, Pedro Portugal, José Varejão
10|14 Capital inflows and euro area long-term interest rates

Daniel Carvalho | Michael Fidora

11|14 Misallocation and productivity in the lead up to the Eurozone crisis

Daniel A. Dias | Carlos Robalo Marquesz | Christine Richmond

12|14 Global value chains: a view from the euro area

João Amador | Rita Cappariello | Robert Stehrer

13|14 A dynamic quantitative macroeconomic model of bank runs

Elena Mattana | Ettore Panetti

14|14 Fiscal devaluation in the euro area: a model-based analysis

S. Gomes | P. Jacquinot | M. Pisani

15|14 Exports and domestic demand pressure: a dynamic panel data model for the euro area countries

Elena Bobeica | Paulo Soares Esteves | António Rua | Karsten Staehr

16|14 Real-time nowcasting the US output gap: singular spectrum analysis at work Miguel de Carvalho | António Rua 
2015

1|15 Unpleasant debt dynamics: can fiscal consolidations raise debt ratios?

Gabriela Castro | Ricardo M. Félix | Paulo Júlio | José R. Maria 


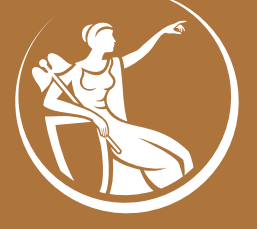

